\title{
Roles of Macrophages in the Development and Treatment of Gut Inflammation
}

\section{OPEN ACCESS}

Edited by:

Qiyuan Yang,

University of Massachusetts Medical

School, United States

Reviewed by:

Sheik Pran Babu Sardar Pasha, University of California, Davis,

United States

Mosharraf Sarker,

Teesside University, United Kingdom

${ }^{*}$ Correspondence:

Hongmei Jiang

jhmndcn@hunau.edu.cn

Gang Liu

gangle.liu@gmail.com

Specialty section

This article was submitted to

Molecular Medicine

a section of the journal

Frontiers in Cell and Developmental

Biology

Received: 03 November 2020

Accepted: 08 February 2021

Published: 02 March 2021

Citation:

Han X, Ding S, Jiang H and Liu G

(2021) Roles of Macrophages in the Development and Treatment of

Gut Inflammation

Front. Cell Dev. Biol. 9:625423.

doi: 10.3389/fcell.2021.625423

\author{
Xuebing Han, Sujuan Ding, Hongmei Jiang* and Gang Liu* \\ College of Bioscience and Biotechnology, Hunan Agricultural University, Hunan Provincial Engineering Research Center \\ of Applied Microbial Resources Development for Livestock and Poultry, Changsha, China
}

Macrophages, which are functional plasticity cells, have the ability to phagocytize and digest foreign substances and acquire pro-(M1-like) or anti-inflammatory (M2-like) phenotypes according to their microenvironment. The large number of macrophages in the intestinal tract, play a significant role in maintaining the homeostasis of microorganisms on the surface of the intestinal mucosa and in the continuous renewal of intestinal epithelial cells. They are not only responsible for innate immunity, but also participate in the development of intestinal inflammation. A clear understanding of the function of macrophages, as well as their role in pathogens and inflammatory response, will delineate the next steps in the treatment of intestinal inflammatory diseases. In this review, we discuss the origin and development of macrophages and their role in the intestinal inflammatory response or infection. In addition, the effects of macrophages in the occurrence and development of inflammatory bowel disease (IBD), and their role in inducing fibrosis, activating $T$ cells, reducing colitis, and treating intestinal inflammation were also reviewed in this paper.

Keywords: macrophages, inflammation, homeostasis, intestinal, treatment

\section{INTRODUCTION}

The intestinal tract is the largest independent immune system in the body. It is continuously exposed to foreign antigens and the distinction between harmful and harmless antigens is necessary for the intestine to ensure an appropriate response to every antigen (Weiner, 2000; Ma et al., 2020a). The gut needs to produce a strong protective immune response to resist the invasion of pathogenic antigens, while similar reactions to harmless antigens such as dietary proteins or symbiotic microorganisms, may lead to chronic inflammatory diseases. Macrophages are phagocytes found in tissues and maintain tissue homeostasis, regulate inflammation, and play a significant role in host protection. There are many microorganisms colonized in the human intestine, and more than 1000 bacterial species in the intestinal ecosystem of a single individual. Among them, Actinobacteria, Bacteroidetes, Firmicutes, Proteobacteria, and Tenericutes are the predominant bacterial phyla, while the abundances of Fusobacteria, Saccharibacteria, Spirochaetes, Synergistetes and Verrucomicrobia are lower (Fassarella et al., 2020).

The production of phagocytic cytotoxic substances by activated macrophages is a key process in the control of intracellular pathogens (Piacenza et al., 2019). The pattern recognition receptors on the surface of macrophages recognize and bind to the corresponding pathogen associated molecular pattern (PAMP) - a specific molecular structure shared by some pathogens-on pathogens, and 
nonspecifically phagocytize and remove pathogenic microorganisms (Ley et al., 2016). Different kinds of microorganisms express different PAMPs, including mainly lipopolysaccharides (LPSs), phosphoteichoic acid, peptidoglycan, and other structures that usually do not exist in the host. Then, the pathogens are phagocytized and digested by macrophages, and the lymphocytes or other immune cells are activated to kill these pathogens (Jain et al., 2019). On the other hand, phagosomes are formed when the pathogen is engulfed by macrophages and fuse with lysosomes to release enzymes and toxic substances, resulting in killing or having cytotoxic effects on bacteria and tumor cells. The intestinal mucosa is the first line of defense for organisms against intestinal pathogens. The lamina propria of the small intestine is the main site of the intestinal immune system, which contains a large number of macrophages, CD4 $\mathrm{T}$ cells, and dendritic cells. These cells play a key role in early resistance to intestinal pathogens. Macrophages play a significant role in many processes, such as the human immune function, parasite infection, and tissue remodeling by secreting cytokines and producing reactive oxygen and nitrogen intermediates. In a broad sense, intestinal macrophages are divided into two categories: resident and inflammatory (Mills et al., 2000). The former maintains intestinal health, while the latter plays an important role in the occurrence of inflammatory reactions. Multiple studies have shown that macrophages are associated with the development of intestinal inflammation and secrete a large number of cytokines and bioactive substances that participate in the inflammatory response (Cummings et al., 2016; Joeris et al., 2017). Herein, we review the origin and development of macrophages and their role in intestinal inflammation and treatment.

\section{INTESTINAL INFLAMMATION}

The healthy gut can control inflammation through its powerful mechanisms, but inflammatory bowel disease (IBD) can occur if the inflammation is not resolved (Murray and Smale, 2012). IBD, which includes Crohn's disease and ulcerative colitis, is a kind of chronic gastrointestinal inflammatory disease with unknown etiology and recurrent attacks (Torres et al., 2017; Ungaro et al., 2017). The pathogenesis of IBD is unknown, but it is believed that the uncontrolled immune response of genetically predisposed individuals to environmental factors and intestinal microorganisms is the cause (Khor et al., 2011; Kostic et al., 2014; de Souza and Fiocchi, 2016; Liu and Stappenbeck, 2016; Ni et al., 2017; Ananthakrishnan et al., 2018). In other words, the combined effects of genetic, microbial, immune, and environmental factors lead to an abnormal and excessive immune response of the commensal microbiota (Wallace et al., 2014). When the intestine is invaded by pathogens, which can cross the damaged intestinal epithelial cell barrier, the intrinsic defense cells in the epithelium, especially the macrophages, will produce pro-inflammatory cytokines after being stimulated, and then release interleukin-1 (IL-1), IL-6, IL-18, transforming growth factor- $\beta$ (TGF- $\beta$ ), and tumor necrosis factor- $\alpha$ (TNF- $\alpha)$. These cytokines directly or indirectly affect the intestinal epithelial cells, leading to the injury or necrosis of these cells, which promotes the occurrence and development of IBD (Figure 1). An over-secretion of cytokines and chronic inflammation are the typical features of IBD, with clinical symptoms of diarrhea, abdominal pain, fever, intestinal obstruction, and disability symptoms of blood or mucus or both (Baumgart and Carding, 2007; Geremia et al., 2014; Geremia and Arancibia-Cárcamo, 2017; Hidalgo-Garcia et al., 2018; Ding et al., 2019b). IBD occurs exclusively in the colon in ulcerative colitis and almost anywhere along the gastrointestinal tract in chronic diarrhea (Jones et al., 2018). In addition, IBD also has the characteristics of intestinal microbiota dysbiosis. Compared with the gut of healthy people, the quantity and diversity of intestinal bacteria is lower in IBD patients (Frank et al., 2007; Lepage et al., 2011; Kostic et al., 2014). In some sufferers, the inflammation of the mucosa is associated with these changes and bacterial factors (Gevers et al., 2014; Franzosa et al., 2019; Lloyd-Price et al., 2019). Some scholars have analyzed the pro-inflammatory and anti-inflammatory pathways of IBD patients, and the results show that the imbalance of immune responses is caused by the change of balance among inflammatory, regulatory and anti-inflammatory cytokines (Bouma and Strober, 2003). When IBD occurs, monocyte infiltration will increase and produce many pro-inflammatory mediators, including TNF $\alpha$, IL-1, IL23, and nitric oxide (Ogino et al., 2013; Bain and Mowat, 2014; Sanders et al., 2014; Magnusson et al., 2016; Joeris et al., 2017). Many types of mucosal immune cells are related to the pathogenesis of IBD: intestinal epithelial cells, innate arm dendritic cells, innate lymphoid cells, neutrophils, macrophages, Foxp $3^{+}$regulatory $\mathrm{T}$ (Treg) cells of the adaptive arm, interferon$\gamma$-producing type 1 helper $\mathrm{T}$ cells (Th1), interferon- $\gamma$ helper $\mathrm{T}$ cells (Th17), and secretory mediators of the adaptive arm of the mucosal immune system-cytokines, chemokines, eicosanoic acid, reactive oxygen species and nitrogen species (Xavier and Podolsky, 2007; Wu et al., 2015). A study has found that, compared with quiescent IBD or the healthy intestine, IBD in active humans was related to the increase of colonic mRNA expression of TNF, IL-1 $\beta$ and IL-6, and of the HLA-DR ${ }^{\text {Int }}: \mathrm{HLA}_{-\mathrm{DR}}{ }^{\mathrm{Hi}}$ and $\mathrm{CD} 14^{\mathrm{Hi}}: \mathrm{CD} 14^{\mathrm{Lo}}$ cell ratios (Jones et al., 2018).

Molecular cues are also responsible for the contribution of intestinal macrophages in the development of IBD. Tolllike receptors (TLRs) play a key role in maintaining intestinal homeostasis. After recognizing PAMPs, TCLs are activated to regulate both innate and adaptive immunity. Innate immunity is regulated by mediating the phosphorylation of $\mathrm{I} \kappa \mathrm{B}$, thereby activating NF- $\mathrm{B}$. Moreover, the proliferation and differentiation of Th1 and Th2 from T cells is regulated by TCLs to regulate adaptive immunity. When these regulations are disturbed, the expression of TLRs increases and the downstream signaling cascade is over activated, resulting in the over production of inflammatory cytokines and IBD ( $\mathrm{Lu}$ et al., 2018). When IBD occurs, it is often accompanied by the death of intestinal epithelial cells (Abraham and Cho, 2009). Epithelial injury and inflammation in IBD patients are usually dependent on TNF (Zeissig et al., 2004). When the production of TNF 


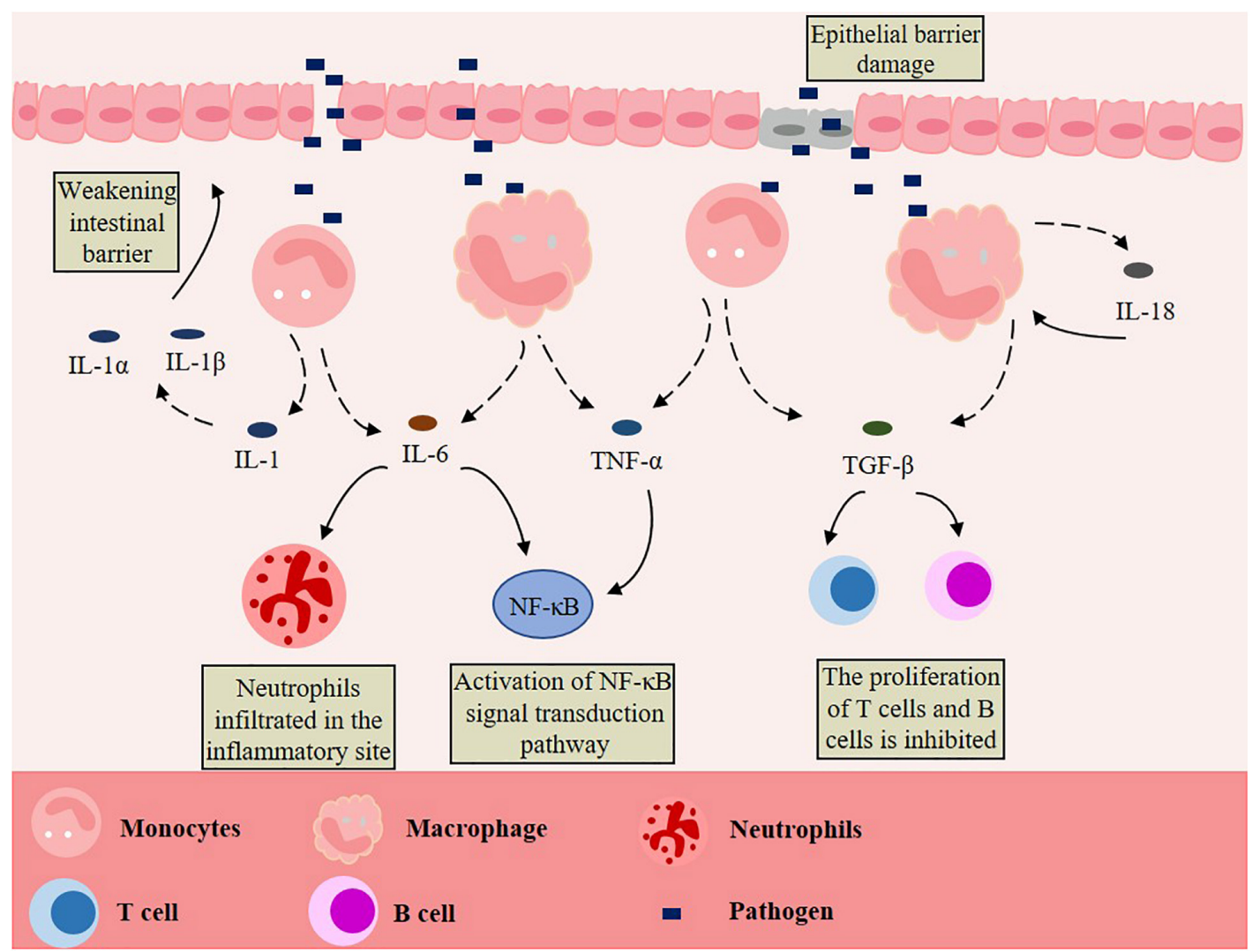

FIGURE 1 | Macrophages promote the development of IBD. Pathogens cross the damaged intestinal epithelial cell barrier and stimulate macrophages to produce pro-inflammatory cytokines, such as interleukin- 1 (IL-1), IL-6, IL-18, transforming growth factor- $\alpha$ (TGF- $\alpha$ ) and tumor necrosis factor- $\beta$ (TNF- $\beta$ ) are released. These act on intestinal epithelial cells directly or indirectly, leading to the injury or necrosis of these cells, thus promoting the occurrence and development of IBD.

increased in IBD, the expression of the TNFAIP3 gene, which encodes A20, also increases. The A20 protein is the negative feedback regulator of $\mathrm{NF}-\kappa \mathrm{B}$. In the intestinal epithelium of IBD patients, A20 is expressed by an intestinal epithelial cell specific promoter and is highly sensitive to intestinal epithelial cell death, intestinal injury, and shock induced by TNF (Garcia-Carbonell et al., 2018).

Generally speaking, IBD often occurs in young individuals, and most patients with IBD are expected live to a normal life due to the progress of medical treatment. Despite the low mortality rate of IBD, the incidence rate is still a serious problem. Moreover, IBD is incurable and increases the risk of lymphoma, cholangiocarcinoma, and colorectal cancer (Samadder et al., 2019; Scharl et al., 2019). Many patients with IBD have to undergo surgery multiple times to relieve symptoms, which may lead to postoperative complications and infections, adversely affecting their quality of life (Torres et al., 2017; Ungaro et al., 2017; Liang et al., 2018). There have been some-although relative few-experiments using immunomodulators for IBD treatment, but the effect of the treatment declines with time (Torres et al., 2017; Ungaro et al., 2017; Friedrich et al., 2019). Tissue reparative programs may also contribute to restoring the barrier, but improper regulation may lead to fibrosis and intestinal structuring due to the dysregulation of intestinal, which is a possible complication of IBD (Rieder and Fiocchi, 2009; Rieder et al., 2017).

\section{ONTOGENY, LOCATION, AND CHARACTERIZATION OF MACROPHAGES}

\section{Origin and Differentiation of Macrophages}

Macrophages are white blood cells located in tissues. In general, it is believed that macrophages are derived from monocytes, and monocytes are derived from precursor cells in bone marrow, which is also known as the granulocyte-macrophage colonyforming unit (GM-CFUc) (Figure 2; van Furth and Cohn, 1968; van Furth et al., 1972). However, whether monocytes differentiate into tissue-specific macrophages in the blood is still controversial. Some scholars believe that monocytes continue to develop and mature in the blood, where they can migrate to different tissues to form cell groups with different functions and structures. According to their function during the migration from blood to tissue, they can be divided into "inflammatory" and "resident" monocytes (Geissmann et al., 2003). The resident 


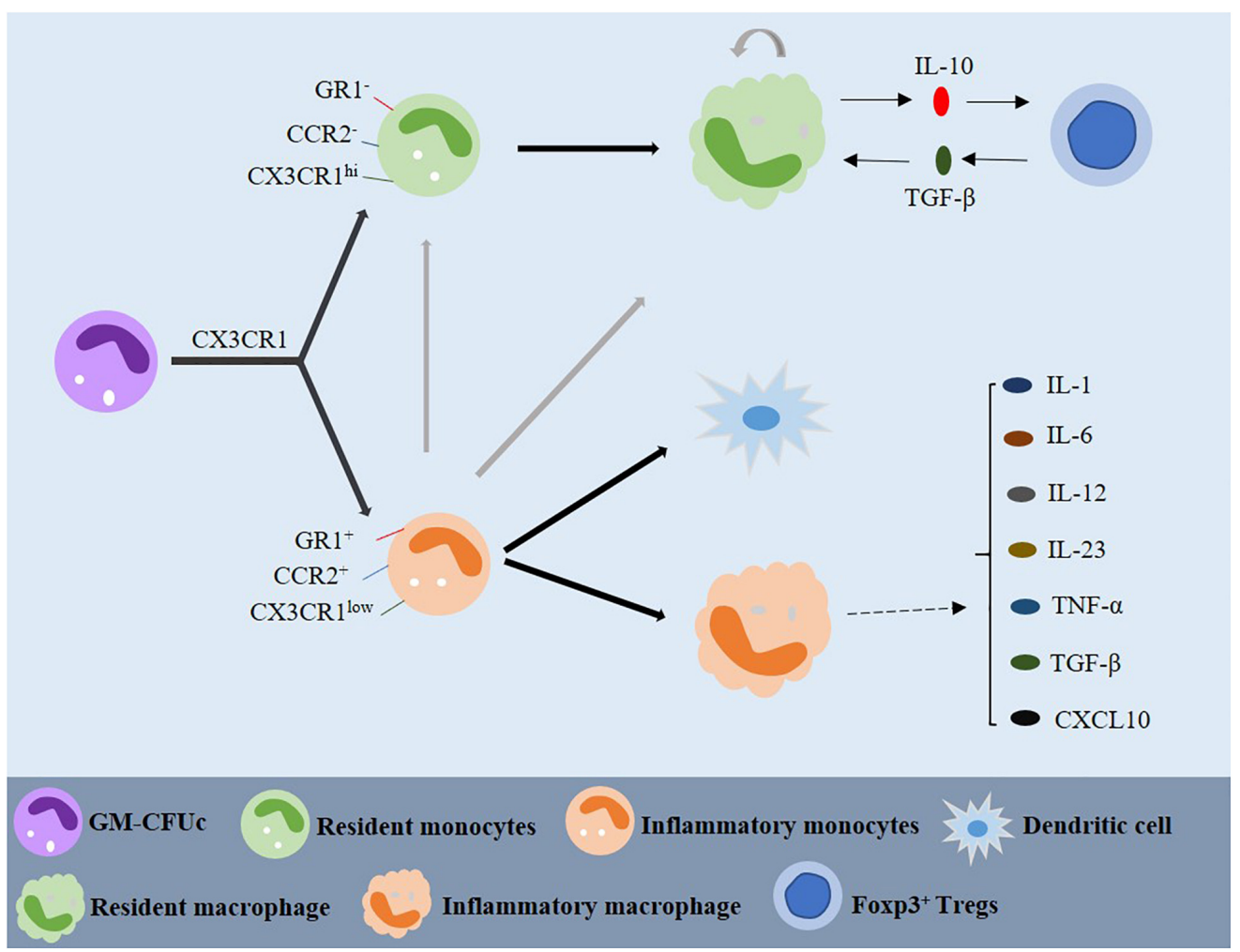

FIGURE 2 | Origin and differentiation of macrophages. GM-CFUc can be divided into resident and inflammatory monocytes by CX3CR1. Inflammatory monocytes may also be one of the sources of resident monocytes. Resident macrophages are usually produced by resident monocytes or, sometimes, by inflammatory monocytes. Resident macrophages and Foxp3 ${ }^{+} \mathrm{T}$ cells play a significant role in maintaining intestinal homeostasis through IL-10 and TGF- $\beta$ dependent mechanisms. When there is inflammation in the intestine, inflammatory monocytes migrate to the intestine and differentiate into dendritic cells and inflammatory macrophages, which can produce a variety of cytokines involved in the inflammatory reaction. GM-CFUc: granulocyte macrophage colony forming unit; IL: interleukin; TNF- $\alpha$ : tumor necrosis factor- $\alpha$; TGF- $\beta$ : transforming growth factor- $\beta$.

monocytes are defined as CCR2 ${ }^{-}, \mathrm{CX} 3 \mathrm{CR} 1^{h i}$, and $\mathrm{GR} 1^{-,}$they exist in the non-inflammatory tissues and have a long half-life. The precursor inflammatory monocytes are CCR2 $2^{+}, \mathrm{CX} 3 \mathrm{CR} 1^{\text {low }}$, and $\mathrm{GR} 1^{+}$are found in the inflammatory tissues, having a short survival time. The two monocyte populations can be distinguished by the expression of CX3CR1, a cell surface marker (Figure 2; Geissmann et al., 2003; Strauss-Ayali et al., 2007). One study has shown that when blood vessels are damaged and infected, the colonized monocytes rapidly invade the tissues, and then initiate the innate immune response and differentiate into macrophages (Figure 2; Geissmann et al., 2003). By contrast, inflammatory monocytes reach the site of inflammatory response and differentiate into inflammatory dendritic cells after infection. It has been demonstrated that inflammatory monocytes can differentiate into inflammatory macrophages, and the migration of resident monocytes may depend on chemical signals from damaged tissues or endothelial cells (Figure 2; Mowat and Bain, 2011).

In the human bone marrow, monocytes can be divided into Ly6 $\mathrm{C}^{l o}$ monocytes and Ly6C $\mathrm{C}^{h i}$ monocytes through the expression of Ly6C/GR1, CCR2, and CX3CR1. Because Ly6C ${ }^{h i}$ monocytes tend to perform functions that traditionally belong to monocytes, they are now called "classical" monocytes. On the other hand, some scholars have proposed that $\mathrm{Ly} 6 \mathrm{C}^{l o}$ monocytes are the precursors of tissue resident macrophages because they do not enter inflammatory tissue (Geissmann et al., 2003). In addition, a study has shown that the "non-classical" Ly6C $\mathrm{C}^{l o}$ monocytes are not used as circulating intermediates, but their main function is to patrol the vascular system and remove necrotic endothelial cells (Carlin et al., 2013). Therefore, Ly6C ${ }^{l o}$ monocytes can be considered the macrophages of the circulatory system in some ways. In the normal colon, monocytes gradually differentiate into resident macrophages. When there is inflammation in the gut, resident macrophages still originate from monocytes in blood circulation but change from anti-inflammatory to inflammatory macrophages with high expression of TLRs. However, studies have shown that Ly6 $\mathrm{C}^{h i}$ monocytes can also be converted to Ly6 $\mathrm{C}^{l o}$ monocytes and returned to the bone marrow to replenish the resident macrophages (Figure 2; Gren and Grip, 2016). Some scholars proposed that resident macrophages also have the characteristics of self-renewal (Figure 2; Bain and Mowat, 2011).

Resident macrophages produce anti-inflammatory cytokines, such as IL-10 and TGF- $\beta$. Studies have reported that IL-10 produced by macrophages has the effect of regulating the expression of Foxp $3^{+}$Tregs, and macrophages highly express the TGF- $\beta$ receptor and participate in the signal transduction of 
activated TGF- $\beta$ (Figure 2; Mowat and Bain, 2011; Weinhage et al., 2015). TGF- $\beta$ can combine with the Foxp3 expressed by Tregs to form $\mathrm{CD}^{+}{ }^{+}$Foxp3 ${ }^{+}$Tregs, which can reduce the activation of macrophages and translocation of NF- $\mathrm{KB}$ in the mucosa (Li et al., 2010).

Some studies have shown that many tissue macrophages do not originate from blood mononuclear cells but exist independently of conventional hematopoiesis and originate from embryonic precursors produced by the yolk sac or fetal liver (Schulz et al., 2012; Hashimoto et al., 2013; Yona et al., 2013; Epelman et al., 2014; Sheng et al., 2015). As we know, the differentiation continuum of monocyte to macrophage exists in intestinal lipoprotein, which has been called the monocyte "waterfall" (Tamoutounour et al., 2012; Bain et al., 2013). Ly6 ${ }^{\text {hi }}$ CX3CR $1^{\text {int }} \mathrm{MHCII}^{-}$monocytes exist at one end of the "waterfall", and their phenotype and morphology are similar to those of their counterparts in the blood. In fact, the expression of molecules of monocytes in the mucosa, including CCR2, VLA1, CD62L, Ly6C and LFA-1, is still preserved; these molecules are related to the chemotaxis and extravasation of circulation (Schridde et al., 2017). First, these monocytes show MHCII expression; Then, the molecules associated with extravasation, including LFA-1, CCR2, and CD62L, are downregulated; Finally, CX3CR1 is upregulated to obtain fully mature macrophages (Tamoutounour et al., 2012; Bain et al., 2013; Schridde et al., 2017). At the same time, it has been proved that the human intestinal mucosa presents a similar "waterfall", with the classic $\mathrm{CD} 14^{h i} \mathrm{CCR} 2{ }^{+} \mathrm{CD} 11 \mathrm{C}^{h i}$ monocytes and mature $\mathrm{CD} 14^{\text {lo }} \mathrm{CCR} 2{ }^{-} \mathrm{CD} 11 \mathrm{C}^{\text {lo }}$ macrophages at the two ends (Bain et al., 2013; Bernardo et al., 2018; Bujko et al., 2018).

Inflammation includes the detection of tissue injury or infection, the subsequent inflammatory response and the final resolution. Monocytes are equipped with a large number of scavengers and pattern recognition receptors, which can react to local danger signals quickly. Their high plasticity enables them to adapt to molecular changes in response to the production of effector molecules that drive inflammation. Although we now have a deeper understanding of the function of Ly6C, more research is needed to explain the molecular mechanism of monocytes acting in a restorative rather than pathological manner.

\section{Distribution of Intestinal Macrophages}

Macrophages play a significant role in regulating intestinal peristalsis. They are distributed throughout the gastrointestinal mucosa, with a large proportion of them being located in the natural layer (LP) near the epithelium and a small part of them appear in the smooth muscle layer of the intestinal wall (Tajima et al., 2012; Gabanyi et al., 2016). In different parts of the gastrointestinal tract, the number of macrophages varies in the intestinal mucosa. Both in humans and rodents, the number of macrophages in the colon and lamina propria was found to be more than that in the small intestine (Nagashima et al., 1996; Denning et al., 2011). However, the number of macrophages follows a continuous gradient trend between the proximal and distal intestines of mice, while the number of macrophages in different parts of the colon was similar in mice and humans (Nagashima et al., 1996; Grainger et al., 2017).

\section{Functional Plasticity of Macrophages}

Generally speaking, macrophages are phagocytes in tissues and play an important role in homeostasis of adipose and tissue, regulation of inflammatory response and defense protection of host. Macrophages have the property of plasticity and can change their physiology, being able to produce different cell populations with different functions, according to environmental cues (Mosser and Edwards, 2008). The activation state of macrophages was initially divided into classically activated M1 macrophages and alternatively activated M2 macrophages. Inflammatory macrophages are usually activated as the M1 phenotype, while resident macrophages usually belong to the activated M2 phenotype. M1 and M2 macrophages are induced by interferon- $\gamma($ IFN- $\gamma)$ and IL-4, respectively, and participate in the anti-microbial response and the reaction of wound healing and tissue remodeling, respectively (Stein et al., 1992; Mills et al., 2000). It is difficult to distinguish M1 and M2 in vivo due to the mixing of activated M1/M2 macrophages caused by the multitude of stimulations, although the polarization state of prototypes M1/M2 has been established in vitro (Martinez and Gordon, 2014). Some studies have shown that macrophages become a continuum of activation states when they are stimulated by certain cytokines or complexes, such as TNF- $\alpha$, LPS, TGF$\beta$, IL-10, IL-13, Glucocorticoid or the immune complex, and macrophage activation with similar but different transcriptional and functional is subsequently produced along the M1/M2 axis (Martinez and Gordon, 2014; Murray et al., 2014; Xue et al., 2014; Murray, 2017). Moreover, some studies have found that macrophages are activated outside the M1-M2 continuum when they are stimulated by high-density lipoproteins, free fatty acids, or chronic-inflammation-related stimulants (Popov et al., 2008; Xue et al., 2014).

The activation and function of macrophages are complex, but the activated states can be identified and distinguished by the abundance of transcription factors, cytokines, and surface molecules (Table 1). For example, M1 macrophages usually produce high levels of pro-inflammatory cytokines, such as TNF- $\alpha$, IL- 6 and IL-12, and promote the induction of nitric oxide synthase (iNOS) and the expression of indoleamine 2,3-dioxygenase in mice and humans, respectively, while M2 macrophages are generally distinguished by stimuli-specific molecules and more general M2 markers (Murray et al., 2014; Xue et al., 2014). CD206 is one such surface marker induced by IL-4/IL-13 and IL-10 in mice and humans, respectively (Stein et al., 1992; Mantovani et al., 2004; Murray et al., 2014). The expression and activity of arginase I also constitute a marker of M2-polarized macrophages in mice, but not in human (Thomas and Mattila, 2014). The expression of IL-10 in several polarization states of M2 macrophages (except for those induced by IL-4/IL13) is higher than for M1 macrophages, making it a frequently used marker of M2 macrophages.

In addition, macrophages can also differentiate into Mregs and TAM, which have different stimulating factors, surface markers, cytokines and functions (Table 1) (Mosser and Edwards, 2008). 
However, it is not clear what causes the change of activation status of macrophages, the reasons may be the recruitment of monocytes and their response to local changes, the repolarization between M1 and M2 macrophages, or a combination of the two (Italiani and Boraschi, 2014). The traditional macrophage polarization model is not sufficient to describe the full range of macrophage activity. Due to the increased heterogeneity of macrophages in the gut, further work is needed to analyze the role of macrophage subsets in health and disease. Many technologies have been used to study the heterogeneity of macrophages. For example, single-cell RNA sequencing has been used for the transcriptomic profiling of haematopoietic cells in humans, and macrophage heterogeneity across multiple anatomical sites was mapped, with diverse subsets being identified (Bian et al., 2020). A rapid three-dimensional (3D) printing method was also used in the research of cell heterogeneity. Tang et al. reported a controllable, repeatable, and quantifiable 3D bioprinting model of the glioblastoma microenvironment, simulating the high cell heterogeneity and cell interaction in the tumor microenvironment (Tang et al., 2020). In addition, macrophages have highly specialized functions in different tissues, and their receptors are also different. They may cooperate or compete for ligand recognition, which will affect their function.

\section{MACROPHAGES IN THE INTESTINAL MUCOSA DURING INFLAMMATION}

\section{Intestinal Homeostasis and Its Disruption During Inflammation}

The gut, which is exposed to pathogens, commensal microbiota, and food antigens, is one of the main interfaces for contact with the outside ambient. The balance between immune responses to pathogens and tolerance is necessary for this bodily niche in order to maintain intestinal homeostasis and body health (Hill and Artis, 2010; Pabst and Mowat, 2012; Belkaid and Hand, 2014). The intestinal epithelium, which is mainly made up of a single layer of intestinal cells, is tightly connected with adjacent cells to form a critical continuous physical barrier, which regulates the selective permeability of luminal content (Odenwald and Turner, 2017; Chelakkot et al., 2018). Except for those in physical barriers, several other types of epithelial cells produced by stem cells, which are located at the base of the intestinal crypt, also play a role in the homeostasis of the body (Clevers and Bevins, 2013; Peterson and Artis, 2014; Johansson and Hansson, 2016; Martens et al., 2018). There is only one mucus layer in the small intestine, while both an internal and outer layer can be found in the colon, making it a habitat for many microbes (Johansson and Hansson, 2016). After passing through the epithelial barrier, the luminal antigens come in contact with the immune cells in the second and third lymphoid organs in the lamina propria (Buettner and Lochner, 2016; Ahluwalia et al., 2017; Da Silva et al., 2017; Mowat, 2018; Tordesillas and Berin, 2018). After the internalization of mononuclear phagocytes, the treated antigens are presented to lymphocytes to induce oral tolerance and interact with the intestinal flora and dietary factors (Hadis et al., 2011; Pabst and Mowat, 2012; Muller et al., 2014; Chinthrajah et al., 2016; Esterházy et al., 2016; Loschko et al., 2016; Nutsch et al., 2016; Belkaid and Harrison, 2017; Kim et al., 2018; Mowat, 2018). Moreover, conventional dendritic cells can polarize naïve $\mathrm{T}$ cells by migration, while macrophages lack the characteristics of active migration, but help to amplify the $\mathrm{T}$ cell response of lymphocytes (Gaudino and Kumar, 2019). In addition, intestinal macrophages maintain $\mathrm{T}$ cell function by scavenging apoptotic/dead cells, secreting cytokines, and remodeling epithelial cells, thus maintaining tissue homeostasis (Zigmond et al., 2012; Ortega-Gómez et al., 2013; Cerovic et al., 2014; Zigmond et al., 2014; Schett and Neurath, 2018; Sugimoto et al., 2019). These processes of active regulation, and $\mathrm{T}$ cell deletion and anergy are associated with maintaining oral tolerance (Sun et al., 2015; Luu et al., 2017; Wawrzyniak et al., 2017; Mowat, 2018). In addition, as a response to microbial induction, conventional dendritic cells also support the conversion of immunoglobulin $\mathrm{M}$ and immunoglobulin $\mathrm{G}$ to immunoglobulin $\mathrm{A}$ on $\mathrm{B}$ cells, which

TABLE 1 | Phenotype of macrophages and its correlation with stimulating factors, surface markers, cytokines, and functions.

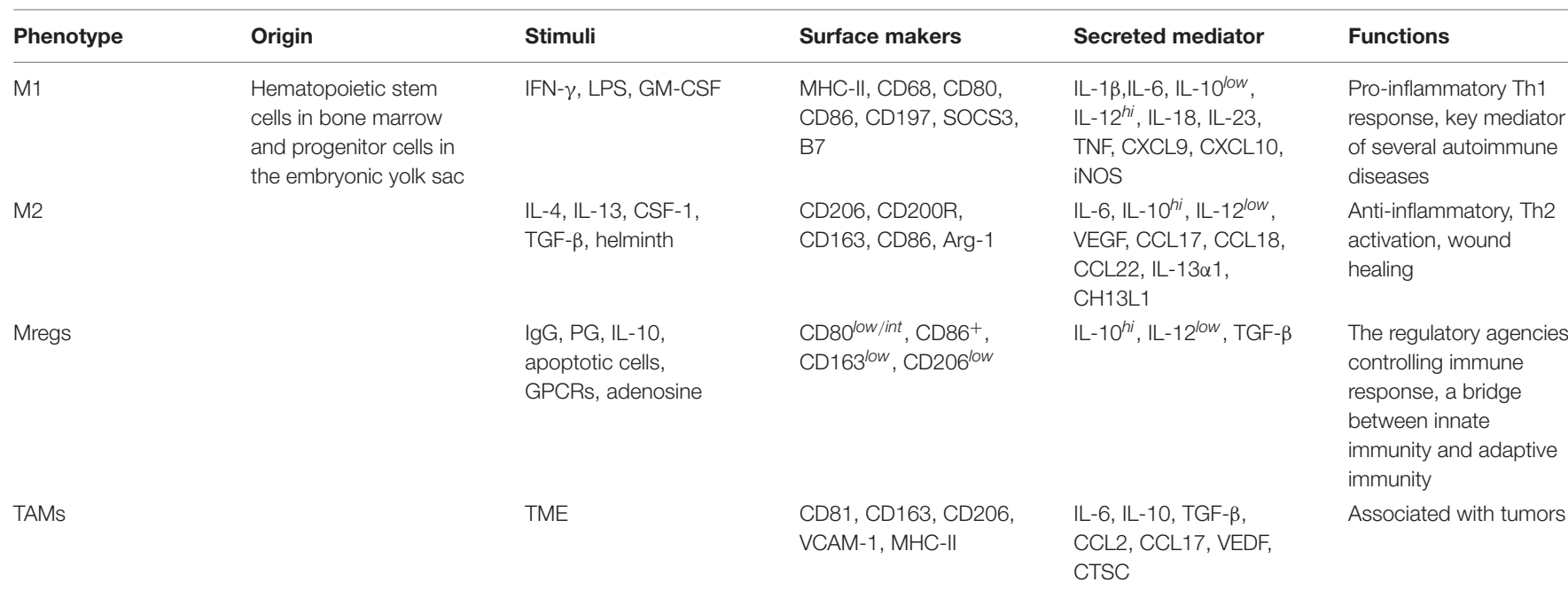


is essential for the homeostasis of the intestinal environment because immunoglobulin A inhibits the interaction between microorganisms and epithelial cells by transporting across the epithelial cell layer (Litinskiy et al., 2002; Macpherson et al., 2018; Castro-Dopico and Clatworthy, 2019).

In general, mononuclear phagocytes control the stability of the intestinal environment and the ability to trigger the immune response to pathogens by maintaining immune tolerance to commensal animals and diet (Hadis et al., 2011; Bain and Mowat, 2014; Cerovic et al., 2014; Kim et al., 2018; Leonardi et al., 2018). Ideally, these immune responses can promote inflammation remission and rapid homeostasis recovery in tissues. However, due to the repeated and abnormal activation of the immune system, the chronic inflammatory microenvironment of IBD will be produced in the body (Caër and Wick, 2020). Destruction of intestinal homeostasis, including an immune response to commensal bacteria, dysfunction of the epithelial barrier function, the reduction of nutrient absorption, and changes in tissue autophagy and oxygenation, can induce the recruitment of immune cells (Maloy and Powrie, 2011; Johansson et al., 2013; Peterson and Artis, 2014; Colgan et al., 2016; Ramakrishnan and Shah, 2016; Odenwald and Turner, 2017; Okumura and Takeda, 2017; Ahluwalia et al., 2018; Mowat, 2018; VanDussen et al., 2018). These intestinal defects are associated with IBD, and the gene expression related to the prognosis variation of Crohn's disease can be detected in mononuclear phagocytes. Thus, we can speculate that mononuclear phagocytes play a significant role in the cellular signaling pathway that regulates tolerance and chronic inflammation in the intestine (Lee et al., 2017).

\section{The Role of Macrophages in Intestinal Inflammation}

The largest macrophage population in the body exists in the gastrointestinal mucosa, which plays a key role in maintaining epithelial and immune homeostasis (Lee et al., 1985; Pull et al., 2005; Isidro and Appleyard, 2016; Guan et al., 2019). When intestinal homeostasis is disturbed, the composition of the intestinal macrophage pool will change greatly. The inflammatory macrophages will accumulate in the intestinal mucosa of patients with Crohn's disease and ulcerative colitis, for example. Compared with $\mathrm{CD} 14^{\text {low }}$, these inflammatory macrophages can be identified by the expression of $\mathrm{CD} 14^{h i}$, which produces multiple inflammatory mediators, such as TNF- $\alpha$, IL-1, IL-6, ROS mediators, and nitric oxide, which makes them different from macrophages in healthy intestines (Thiesen et al., 2014).

Ly6C $^{\text {hi }}$ monocytes and their derivatives play a significant role in intestinal pathology (Bain and Schridde, 2018). When inflammation occurs in the gut, classical monocytes (Ly6C ${ }^{h i}$ ) respond to the stimulation of Toll-like receptors in a highly proinflammatory manner, expressing reactive oxygen intermediates (Figure 3; Varol et al., 2009; Weber et al., 2011; Rivollier et al., 2012; Tamoutounour et al., 2012; Zigmond et al., 2012; Bain et al., 2013). CD11c $c^{\text {high }} \mathrm{CCR} 2^{+} \mathrm{CX} 3 \mathrm{CR} 1^{+}$monocytes infiltrate in the colonic mucosa of IBD patients in a CCR2-dependent manner and cannot completely differentiate into macrophages and produce pro-inflammatory cytokines (Bernardo et al., 2018). Intestinal macrophages in IBD patients produce more pro-inflammatory cytokines, which promote or perpetuate the pathological environment (Kamada et al., 2008; Kamada et al., 2009; Lissner et al., 2015; Barman et al., 2016; Friedrich et al., 2019). In patients with Crohn's diseases, some factors, such as IFN- $\gamma$, induce the differentiation of inflammatory monocytes and the secretion of IL-23, thus creating a vicious circle of inflammation (Kamada et al., 2008). In addition, other mechanisms and disease-related changes in the function of macrophages may also promote the occurrence and development of IBD. For instance, TREM-1 ${ }^{+}$macrophages, which are mainly immature macrophages, increase in frequency and number in patients with IBD, especially in the active lesion area (Schenk et al., 2007; Brynjolfsson et al., 2016). It has also been suggested that bacterial clearance of intestinal macrophages in patients with IBD is impaired, and patients with Crohn's disease phenotype mainly through dysfunctional autophagy (Smith et al., 2009; Schwerd et al., 2017). After the removal of infectious or inflammatory factors, the intestinal tract must be restored to balance so that a chronic inflammatory reaction will not follow. At the same time, the macrophage pool changes significantly. During colitis in mice, the expansion rate of CX3CR $1^{\text {int }}$ macrophages returned to normal (Zigmond et al., 2012). On the other hand, Ly6C ${ }^{\text {hi }}$ monocytes supplement CX3CR $1^{h i}$ macrophages in intestinal homeostasis. Once the inflammatory response begins to subside, some of the induced Ly6 $\mathrm{C}^{\text {hi }}$ cells may be transformed into resident macrophages with anti-inflammatory effects and may play an active role in tissue injury. IL-1 $\beta$ is believed to be induced mainly by monocytes, and its susceptibility to chemically induced colitis is reduced due to its neutralization (Seo et al., 2015). Meanwhile, the selective ablation of Tnfa in Ly6 $\mathrm{C}^{h i}$ monocytes also reduces the development of colitis (Varol et al., 2009). Mice with defective recruitment of inflammatory mucosal monocytes, which is due to the neutralization or deletion of CCL2, CCR2 or $\beta 7$ integrins, are protected from colitis induced by DSS (Platt et al., 2010; Takada et al., 2010; Zigmond et al., 2012; Bain et al., 2013; Becker et al., 2016; Schippers et al., 2016).

There are other additional functions of Ly6C monocytes (Figure 3). Studies have shown that CCL2, CCL3 and CCL11 may come from $\mathrm{Ly} 6 \mathrm{C}^{h i}$ and play a role in recruiting innate immune effector cells in the gut (Waddell et al., 2011; Schulthess et al., 2012; Bain and Mowat, 2014). Ly6C ${ }^{h i}$ monocytes can also prevent immunopathology by inhibiting the production of TNF- $\alpha$ and ROI by local neutrophils (Grainger et al., 2013). Furthermore, intestinal macrophages participate in tissue repair and fibrosis (Figure 3; Karin and Clevers, 2016; Vannella and Wynn, 2017). Some with Crohn's disease have symptoms of intestinal fibrostenosis, while others develop fibrosis complications several years later (Rieder et al., 2017). Another study has shown that in the colon of patients with Crohn's disease with stenosis, the number of IL-36 $\alpha^{+}$macrophages in the intestine is increased (Scheibe et al., 2019). The direct effect of IL-36 on human mesenchymal cells leads to profibrosis transcription, which indicates that intestinal fibrosis in patients with IBD can be induced by the increase of IL $36 \alpha^{+}$macrophages 


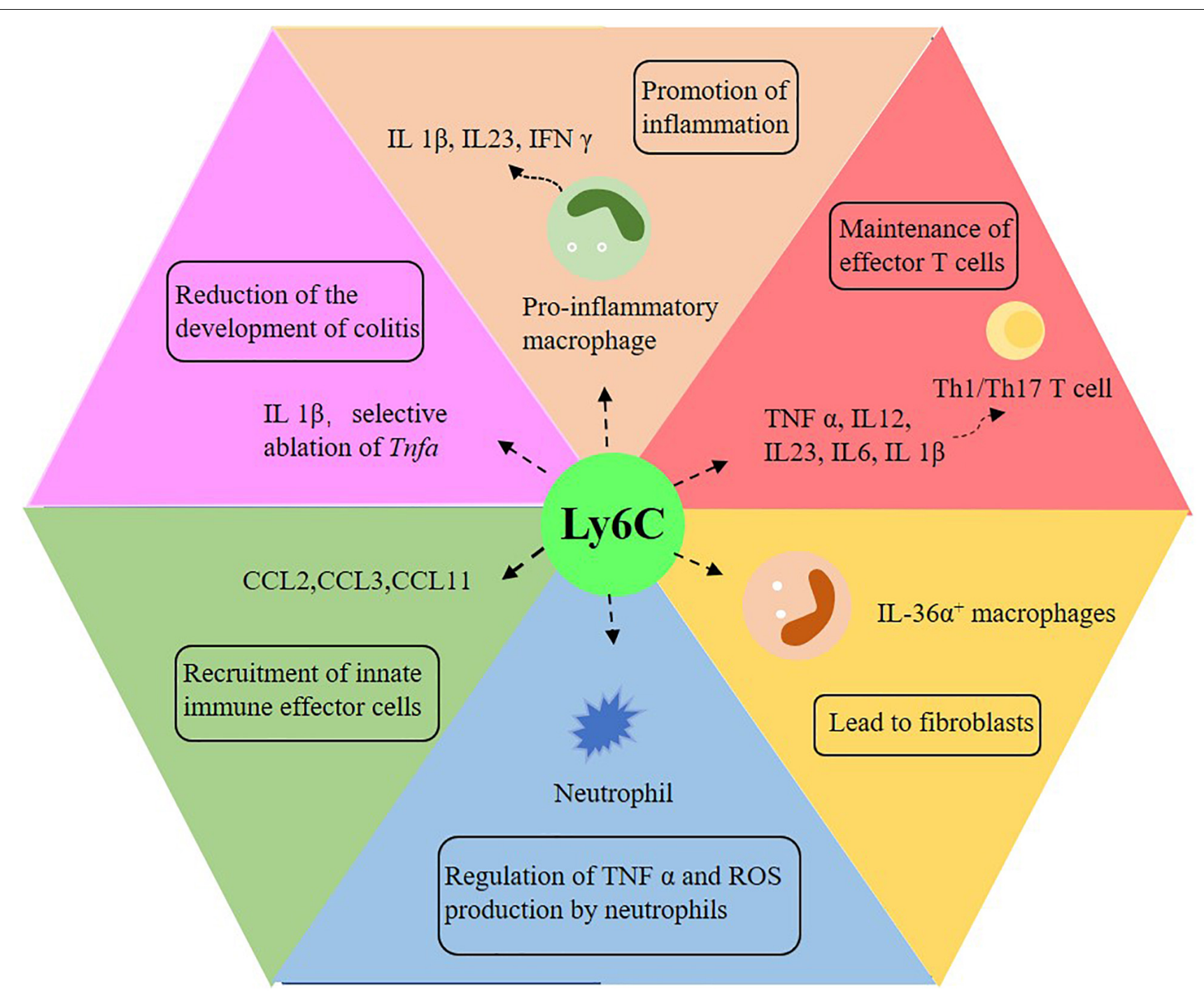

FIGURE 3 | The role of Ly6C monocytes in intestinal inflammation. Ly6C plays an important role in promoting intestinal inflammation, reducing colitis, activating T cells, promoting tissue fibrosis, regulating neutrophils and recruiting innate immune effector cells. IL: interleukin; TNF- $\alpha$ : tumor necrosis factor- $\alpha$; IFN- $\gamma$ : interferon- $\gamma$; Th1: interferon- $\gamma$-producing type 1 helper T cells; Th17: interferon- $\gamma$-producing helper $\mathrm{T}$ cells.

(Bettenworth and Rieder, 2017; Salvador et al., 2018; Scheibe et al., 2019). Other studies have reported that immature macrophages are always close to activated fibroblasts in the intestinal mucosa of patients with Crohn's disease, and immature macrophages, as well as conventional dendritic cells 2 , activate fibroblasts to induce intestinal inflammation by oncostatin M/OSMR signaling (West et al., 2017; Martin et al., 2019; Smillie et al., 2019). Some genes expressed by intestinal macrophages also affect the development of intestinal inflammation. For example, the gene ablation of GPBAR1, a G protein-coupled receptor that is highly expressed in macrophages, enhances the recruitment of classically activated macrophages in the colonic lamina propria and aggravates the severity of inflammation (Biagioli et al., 2017).

Macrophages also play a role in the activation of $\mathrm{T}$ cells (Figure 3). Some studies have shown that, in patients with Crohn's disease, intestinal macrophages can induce the proliferation of naïve $\mathrm{CD} 4^{+} \mathrm{T}$ cells and the expression of integrin $\beta-7$ and CCR9, while other works deem mature macrophages from patients with ulcerative colitis unable to inhibit the proliferation of T cells (Barman et al., 2016). In addition, CD14 ${ }^{h i}$ monocytes/macrophages in the IBD mucosa can produce IL23 and express CD40 and CD80 to support the function of pathogenic T cells (Rugtveit et al., 1997; Carlsen et al., 2006; Kamada et al., 2008). Intestinal macrophages in patients with Crohn's disease induce the Th1 and Th17 polarization of naïve $\mathrm{CD}^{+} \mathrm{T}$ cells, which seems to be caused by the accumulation of immature macrophages in the total macrophage population of patients with Crohn's disease (Kamada et al., 2009; Ogino et al., 2013). In fact, it has been proved by previous studies that immature macrophages from patients with IBD mainly produce IL-1 $\beta$ to induce Th17 cells and pathological IFN- $\gamma^{+}$ 
IL- $17^{+} \mathrm{T}$ cells, which come from autologous colon $\mathrm{CD} 4^{+} \mathrm{T}$ cells (Ramesh et al., 2014; Chapuy et al., 2019; Chapuy et al., 2020).

\section{The Role of Intestinal Macrophages in the Treatment of Inflammation and Diseases}

There are many methods to treat IBD, and regulating macrophage activation is one of them. In fact, it has been considered an attractive treatment for IBD to increase the phenotype of antiinflammatory M2 (Hidalgo-Garcia et al., 2018). Endoplasmic reticulum stress, which is involved in the regulation of IEC inflammatory injury, is common in IBD patients (Woehlbier and Hetz, 2011; Hosomi et al., 2015). Grp78 is a marker of endoplasmic reticulum stress, and its expression is increased in inflammatory IEC. However, after increasing the expression of IL-10, the expression of Grp78 decreases, and endoplasmic reticulum stress is inhibited (Shkoda et al., 2007). IL-10 inhibits the NF- $\kappa \mathrm{B}$ RelA phosphorylation induced by TNF by regulating Grp78, the expression of pro-inflammatory cytokines is subsequently down-regulated, and the IEC barrier function is maintained. According to a previous study, the neutralization of IL-10/TGF- $\beta$ or alternatively activated macrophages did not show resistance to colitis induced by DSS in mice infected with schistosome (Smith et al., 2007). Parasites inhibited colitis induced by DSS through a new colonic infiltrating macrophage population-i.e., the schistosome infection stimulates a new macrophage population that preferentially migrates to the colonic LP, where it can inhibit colitis (Smith et al., 2007). This finding highlights a variety of immunomodulatory macrophage activation states. It is worth noting that infliximab, a monoclonal antibody of anti-TNF- $\alpha$, has been successfully used in the treatment of human IBD, and the regulatory macrophages $\mathrm{CD} 68^{+} \mathrm{CD} 206^{+}$were induced in patients with IBD responsive to treatment (Vos et al., 2012; Danese et al., 2015). Some studies have proved that macrophages are significant for the treatment of IBD. For example, alternative activated macrophages can activate the Wnt signaling pathway, which is related to ulcerative colitis, and promote mucosal repair in IBD, while Yes-associated protein (YAP), a Hippo pathway molecule, can aggravate the occurrence of IBD by regulating macrophage polarization and the imbalance of intestinal flora homeostasis (Cosín-Roger et al., 2016; Zhou et al., 2019).

Macrophages play an important role in in the treatment of colitis. For example, it has been found that intracolonic administration of chromofungin can induce macrophages to enter alternatively activated macrophages (AAM), which reduce the deposition of colonic collagen and maintain the homeostasis of intestinal epithelial cells, thus protecting colitis induced by DSS (Eissa et al., 2017; Ding et al., 2019a). MicroRNAs (miRNAs), which are noncoding RNAs, are essential for many biological processes in fine tuning. In macrophages, miR-155 acts as a pro-inflammatory regulator by promoting M2 polarization or affecting NF-кB signal transduction (Vigorito et al., 2013; Zhang et al., 2016). Li et al. found the central role of alternative M2 skewing of miR-155 in colitis and suggested that macrophages might be the main target of treatment (Li et al., 2018). The
Grb2-associated binding protein 2 (Gab2), which plays a role in regulating the activation of macrophages and $\mathrm{T}$ cells, and Grb2associated binding protein 3 (Gab3), which is highly expressed in some immune cell types, redundantly regulate the activation of macrophages and $\mathrm{CD}^{+} \mathrm{T}$ cells to inhibit colitis (Uno et al., 2010; Bezman et al., 2012; Best et al., 2013; Festuccia et al., 2014; Kaneda et al., 2016; Wang et al., 2019; Ma et al., 2020b). Human catestatin (hCT), which has immunomodulatory properties, can reduce the severity of inflammatory recurrence by regulating M1 macrophages and releasing pro-inflammatory cytokines (Zhang et al., 2009; Rabbi et al., 2017). Triggering receptor expressed on myeloid cells-1 (TREM-1) is a pattern recognition receptor (PRR) of the surface immunoglobulin receptor superfamily and is expressed by activated macrophages. A study has found that when TREM-1 is deficient, the number of M1 macrophages, which produce IL-1 $\beta$, in DSS-treated colons decreases, and the damage mediated by DSS can be alleviated by providing TREM-1 expressing macrophages to TREM-1 deficient mice (Yang et al., 2019). Other studies have found that vitamin D supplementation can also reduce the severity of Crohn's disease, and its active form, 1,25-dihydroxyvitamin D (1,25D), can inhibit the secretion of pro-inflammatory cytokines by macrophages (Dionne et al., 2017). Moreover, 1,25 D is also very important for the regulation of bone homeostasis and various immune responses (Hewison, 2012).

In addition to inhibiting intestinal inflammation, macrophages also play a significant role in other diseases. For example, REG3 $\gamma$ is a secretory antimicrobial lectin and REG3 $\gamma$-associated Lactobacillus can enlarge the macrophage pools in the intestinal lamina propria, spleen and adipose tissue. The anti-inflammatory macrophages induced by REG3 $\gamma$ associated Lactobacillus in the lamina propria may migrate to the adipose tissue and participate in the resistance to high-fat-dietmediated obesity, and adipose tissue homeostasis (Huang et al., 2017). Since the gastrointestinal tract contains many HIV target cells, it has become the main site of HIV infection. Some studies have shown that Toll-like receptor 3 activation of macrophages can produce a variety of intracellular HIV limiting factors and effectively inhibit HIV infection (Wang et al., 2013; Zhou et al., 2013). The supernatant of activated intestinal epithelial cells can induce macrophages to express several key HIV limiting factors, thus inhibiting the replication of HIV (Guo et al., 2018). Whether in mice or human, the cross-talk between liver and intestine is vital in the development of metabolic diseases (Zhang et al., 2010; Qin et al., 2014). For example, non-alcoholic fatty liver disease is usually accompanied by changes in the intestinal microflora and bacterial overgrowth these are related to increased intestinal permeability and pathological bacterial translocation, in which macrophages may also be involved (Bain and Mowat, 2014; Hundertmark et al., 2018). Macrophage inducible C-type lectin expressed on macrophages may contribute to the integrity of the intestinal barrier, but in the advanced stages of chronic liver disease, once the intestinal barrier leaks, it seems to cause inflammation and fibrosis (Schierwagen et al., 2020). Receptorinteracting protein (RIP)-3, a member of the serine threonine kinase family, is the central mediator of necrosis and is associated with many human diseases (Ramachandran et al., 2013; 
Roychowdhury et al., 2013; Linkermann and Green, 2014). It has been shown that the deficiency of RIP3 can inhibit macrophage accumulation and reduce inflammation in mice by inhibiting the TLR4-NF-kB pathway, and thus may be a potential therapeutic target for immune-mediated liver fibrosis (Wei et al., 2019).

Cytokine blockade has been used to suppress intestinal inflammation, but there are still some problems that should be considered, such as the prediction of the therapeutic effect and its prospect. Treating IBD by treating anti-tumor factors is an important breakthrough. However, many treatments have not achieved satisfactory results, and although some treatments are promising in animal models, they have not yet undergone rigorous clinical trials. Moreover, the deficiency of intestinal macrophages may increase the susceptibility to infection and inhibit the activity of tissue repair. Therefore, the potential risks associated with this immunotherapy require careful monitoring procedures. Other ways to improve intestinal homeostasis may consist of promoting the anti-inflammatory effects of macrophages. It is worth noting that, due to their high phagocytic capacity, intestinal macrophages can be promoted through "delivery systems" such as nanomaterials and biomaterials. Finally, the reprogramming of macrophages with metabolites may be a promising method to inhibit intestinal inflammation.

\section{SUMMARY AND PROSPECT}

This paper reviews the origin, development, and function of macrophages and their role in intestinal inflammation and treatment. In the past few years, we have made significant progress in understanding the ontogeny and differentiation of intestinal macrophages. Advancements have been made in the recognition and regulation of tissue-specific phenotypes and functional environmental signals as well. Macrophages not only have the function of phagocytizing pathogens, but can also secrete

\section{REFERENCES}

Abraham, C., and Cho, J. H. (2009). Inflammatory bowel disease. N. Engl. J. Med. 361, 2066-2078. doi: 10.1056/NEJMra0804647

Ahluwalia, B., Magnusson, M. K., and Öhman, L. (2017). Mucosal immune system of the gastrointestinal tract: maintaining balance between the good and the bad. Scand. J. Gastroenterol. 52, 1185-1193.doi: 10.1080/00365521.2017.1349173

Ahluwalia, B., Moraes, L., Magnusson, M. K., and Öhman, L. (2018). Immunopathogenesis of inflammatory bowel disease and mechanisms of biological therapies. Scand. J. Gastroenterol. 53, 379-389.doi: 10.1080/ 00365521.2018.1447597

Ananthakrishnan, A. N., Bernstein, C. N., Iliopoulos, D., Macpherson, A., Neurath, M. F., Ali, R. A. R., et al. (2018). Environmental triggers in IBD: a review of progress and evidence. Nat. Rev. Gastroenterol. Hepatol. 15, 39-49.doi: 10.1038/ nrgastro.2017.136

Bain, C. C., and Mowat, A. M. (2011). Intestinal macrophages - specialised adaptation to a unique environment. Eur. J. Immunol. 41, 2494-2498.doi: 10. 1002/eji.201141714

Bain, C. C., and Mowat, A. M. (2014). Macrophages in intestinal homeostasis and inflammation. Immunol. Rev. 260, 102-117.doi: 10.1111/imr.12192

Bain, C. C., and Schridde, A. (2018). Origin, differentiation, and function of intestinal macrophages. Front. Immunol. 9:2733. doi: 10.3389/fimmu.2018. 02733 a variety of cytokines under certain conditions and combine with different immune cells to participate in the occurrence, development, and persistence of IBD in different ways. At the same time, macrophages play a role in treating IBD, inhibiting colitis, maintaining adipose tissue homeostasis, and inhibiting HIV infection. In conclusion, macrophages are vital in gut homeostasis and immune defense. However, many aspects of intestinal macrophages still need to be explored. For example, the understanding of heterogeneity in the septum of intestinal macrophages needs to be more complete. An important feature of IBD is pro-inflammatory monocyte/macrophage accumulation. Therefore, it is very important to elucidate the exact character of the molecular factors that control the differentiation of monocyte/macrophage, the changes of these factors in the course of disease, the local regulation, and long-term effects. In addition, the study of the interaction between macrophages and other cells, intestinal microorganisms and metabolites will also contribute to the treatment of intestinal inflammation.

\section{AUTHOR CONTRIBUTIONS}

$\mathrm{XH}$ did the writing. SD did the writing-review and editing. $\mathrm{HJ}$ did the supervision. GL did the funding acquisition. All authors contributed to the article and approved the submitted version.

\section{FUNDING}

This study was supported by National Natural Science Foundation of China (No. 31772642), Hunan Provincial Science and Technology Department (2020NK2004, 2019TP2004, and 2016TP2005), Double First-Class Construction Project of Hunan Agricultural University (SYL201802003), and China Postdoctoral Science Foundation (2018M632963 and 2019T120705).

Bain, C. C., Scott, C. L., Uronen-Hansson, H., Gudjonsson, S., Jansson, O., Grip, O., et al. (2013). Resident and pro-inflammatory macrophages in the colon represent alternative context-dependent fates of the same Ly6Chi monocyte precursors. Mucosal. Immunol. 6, 498-510.doi: 10.1038/mi.2012.89

Barman, S., Kayama, H., Okuzaki, D., Ogino, T., Osawa, H., Matsuno, H., et al. (2016). Identification of a human intestinal myeloid cell subset that regulates gut homeostasis. Int. Immunol. 28, 533-545.doi: 10.1093/intimm/dxw034

Baumgart, D. C., and Carding, S. R. (2007). Inflammatory bowel disease: cause and immunobiology. Lancet 369, 1627-1640.doi: 10.1016/s0140-6736(07)60750-8

Becker, F., Kurmaeva, E., Gavins, F. N., Stevenson, E. V., Navratil, A. R., Jin, L., et al. (2016). A critical role for monocytes/macrophages during intestinal inflammation-associated Lymphangiogenesis. Inflamm. Bowel. Dis. 22, 13261345.doi: $10.1097 / \mathrm{mib} .0000000000000731$

Belkaid, Y., and Hand, T. W. (2014). Role of the microbiota in immunity and inflammation. Cell 157, 121-141.doi: 10.1016/j.cell.2014.03.011

Belkaid, Y., and Harrison, O. J. (2017). Homeostatic immunity and the microbiota. Immunity 46, 562-576.doi: 10.1016/j.immuni.2017.04.008

Bernardo, D., Marin, A. C., Fernández-Tomé, S., Montalban-Arques, A., Carrasco, A., Tristán, E., et al. (2018). Human intestinal pro-inflammatory CD11c(high)CCR2(+)CX3CR1(+) macrophages, but not their tolerogenic CD11c(-)CCR2(-)CX3CR1(-) counterparts, are expanded in inflammatory bowel disease. Mucosal. Immunol. 11, 1114-1126.doi: 10.1038/s41385-0180030-7 
Best, J. A., Blair, D. A., Knell, J., Yang, E., Mayya, V., Doedens, A., et al. (2013). Transcriptional insights into the CD8(+) $\mathrm{T}$ cell response to infection and memory T cell formation. Nat. Immunol. 14, 404-412.doi: 10.1038/ni.2536

Bettenworth, D., and Rieder, F. (2017). Pathogenesis of intestinal fibrosis in inflammatory bowel disease and perspectives for therapeutic implication. Dig. Dis. 35, 25-31.doi: 10.1159/000449079

Bezman, N. A., Kim, C. C., Sun, J. C., Min-Oo, G., Hendricks, D. W., Kamimura, Y., et al. (2012). Molecular definition of the identity and activation of natural killer cells. Nat. Immunol. 13, 1000-1009.doi: 10.1038/ni.2395

Biagioli, M., Carino, A., Cipriani, S., Francisci, D., Marchianò, S., Scarpelli, P., et al. (2017). The bile acid receptor GPBAR1 regulates the M1/M2 phenotype of intestinal macrophages and activation of GPBAR1 rescues mice from murine colitis. J. Immunol. 199, 718-733.doi: 10.4049/jimmunol.1700183

Bian, Z., Gong, Y., Huang, T., Lee, C. Z. W., Bian, L., Bai, Z., et al. (2020). Deciphering human macrophage development at single-cell resolution. Nature 582, 571-576.doi: 10.1038/s41586-020-2316-7

Bouma, G., and Strober, W. (2003). The immunological and genetic basis of inflammatory bowel disease. Nat. Rev. Immunol. 3, 521-533.doi: 10.1038/ nri1132

Brynjolfsson, S. F., Magnusson, M. K., Kong, P. L., Jensen, T., Kuijper, J. L., Håkansson, K., et al. (2016). An antibody against triggering receptor expressed on myeloid cells 1 (TREM-1) dampens proinflammatory cytokine secretion by lamina propria cells from patients with IBD. Inflamm. Bowel. Dis. 22, 1803-1811.doi: 10.1097/mib.0000000000000822

Buettner, M., and Lochner, M. (2016). Development and function of secondary and tertiary lymphoid organs in the small intestine and the colon. Front. Immunol. 7:342. doi: 10.3389/fimmu.2016.00342

Bujko, A., Atlasy, N., Landsverk, O. J. B., Richter, L., Yaqub, S., Horneland, R., et al. (2018). Transcriptional and functional profiling defines human small intestinal macrophage subsets. J. Exp. Med. 215, 441-458. doi: $10.1084 /$ jem.20170057

Caër, C., and Wick, M. J. (2020). Human intestinal mononuclear phagocytes in health and inflammatory bowel disease. Front. Immunol. 11:410. doi: 10.3389/ fimmu.2020.00410

Carlin, L. M., Stamatiades, E. G., Auffray, C., Hanna, R. N., Glover, L., VizcayBarrena, G., et al. (2013). Nr4a1-dependent Ly6C(low) monocytes monitor endothelial cells and orchestrate their disposal. Cell 153, 362-375.doi: 10.1016/ j.cell.2013.03.010

Carlsen, H. S., Yamanaka, T., Scott, H., Rugtveit, J., and Brandtzaeg, P. (2006). The proportion of CD40+ mucosal macrophages is increased in inflammatory bowel disease whereas CD40 ligand (CD154)+ T cells are relatively decreased, suggesting differential modulation of these costimulatory molecules in human gut lamina propria. Inflamm. Bowel. Dis. 12, 1013-1024.doi: 10.1097/01.mib. 0000234135.43336 .72

Castro-Dopico, T., and Clatworthy, M. R. (2019). IgG and Fc $\gamma$ receptors in intestinal immunity and inflammation. Front. Immunol. 10:805. doi: 10.3389/ fimmu.2019.00805

Cerovic, V., Bain, C. C., Mowat, A. M., and Milling, S. W. (2014). Intestinal macrophages and dendritic cells: what's the difference? Trends Immunol. 35, 270-277.doi: 10.1016/j.it.2014.04.003

Chapuy, L., Bsat, M., Rubio, M., Sarkizova, S., Therrien, A., Bouin, M., et al. (2020). IL-12 and Mucosal CD14+ monocyte-like cells induce IL-8 in colonic memory CD4+ T cells of patients with ulcerative colitis but not crohn's disease. J. Crohns. Colitis 14, 79-95.doi: 10.1093/ecco-jcc/jjz115

Chapuy, L., Bsat, M., Sarkizova, S., Rubio, M., Therrien, A., Wassef, E., et al. (2019). Two distinct colonic CD14(+) subsets characterized by single-cell RNA profiling in Crohn's disease. Mucosal. Immunol. 12, 703-719.doi: 10.1038/ s41385-018-0126-0

Chelakkot, C., Ghim, J., and Ryu, S. H. (2018). Mechanisms regulating intestinal barrier integrity and its pathological implications. Exp. Mol. Med. 50:103. doi: 10.1038/s12276-018-0126-x

Chinthrajah, R. S., Hernandez, J. D., Boyd, S. D., Galli, S. J., and Nadeau, K. C. (2016). Molecular and cellular mechanisms of food allergy and food tolerance. J. Allergy Clin. Immunol. 137, 984-997. doi: 10.1016/j.jaci.2016.02.004

Clevers, H. C., and Bevins, C. L. (2013). Paneth cells: maestros of the small intestinal crypts. Annu. Rev. Physiol. 75, 289-311.doi: 10.1146/annurev-physiol-030212183744
Colgan, S. P., Campbell, E. L., and Kominsky, D. J. (2016). Hypoxia and mucosal inflammation. Annu. Rev. Pathol. 11, 77-100.doi: 10.1146/annurev-pathol012615-044231

Cosín-Roger, J., Ortiz-Masiá, D., Calatayud, S., Hernández, C., Esplugues, J. V., Barrachina, M. D., et al. (2016). The activation of Wnt signaling by a STAT6dependent macrophage phenotype promotes mucosal repair in murine IBD. Mucosal. Immunol. 9, 986-998.doi: 10.1038/mi.2015.123

Cummings, R. J., Barbet, G., Bongers, G., Hartmann, B. M., Gettler, K., Muniz, L., et al. (2016). Different tissue phagocytes sample apoptotic cells to direct distinct homeostasis programs. Nature 539, 565-569.doi: 10.1038/nature20138

Da Silva, C., Wagner, C., Bonnardel, J., Gorvel, J. P., and Lelouard, H. (2017). The peyer's patch mononuclear phagocyte system at steady state and during infection. Front. Immunol. 8:1254. doi: 10.3389/fimmu.2017.01254

Danese, S., Vuitton, L., and Peyrin-Biroulet, L. (2015). Biologic agents for IBD: practical insights. Nat. Rev. Gastroenterol. Hepatol. 12, 537-545.doi: 10.1038/ nrgastro.2015.135

de Souza, H. S., and Fiocchi, C. (2016). Immunopathogenesis of IBD: current state of the art. Nat. Rev. Gastroenterol. Hepatol. 13, 13-27.doi: 10.1038/nrgastro. 2015.186

Denning, T. L., Norris, B. A., Medina-Contreras, O., Manicassamy, S., Geem, D., Madan, R., et al. (2011). Functional specializations of intestinal dendritic cell and macrophage subsets that control Th17 and regulatory $\mathrm{T}$ cell responses are dependent on the T cell/APC ratio, source of mouse strain, and regional localization. J. Immunol. 187, 733-747.doi: 10.4049/jimmunol.1002701

Ding, S., Ma, Y., Liu, G., Yan, W., Jiang, H., Fang, J., et al. (2019a). Lactobacillus brevis Alleviates DSS-induced colitis by reprograming intestinal microbiota and influencing serum metabolome in murine model. Front. Physiol. 10:1152. doi: 10.3389/fphys.2019.01152

Ding, S., Xu, S., Ma, Y., Liu, G., Jang, H., Fang, J., et al. (2019b). Modulatory mechanisms of the NLRP3 inflammasomes in diabetes. Biomolecules 9:850.doi: 10.3390/biom 9120850

Dionne, S., Duchatelier, C. F., and Seidman, E. G. (2017). The influence of vitamin D on M1 and M2 macrophages in patients with Crohn's disease. Innate. Immun. 23, 557-565.doi: 10.1177/1753425917721965

Eissa, N., Hussein, H., Kermarrec, L., Grover, J., Metz-Boutigue, M. E., Bernstein, C. N., et al. (2017). Chromofungin ameliorates the progression of colitis by regulating alternatively activated macrophages. Front. Immunol. 8:1131. doi: 10.3389/fimmu.2017.01131

Epelman, S., Lavine, K. J., Beaudin, A. E., Sojka, D. K., Carrero, J. A., Calderon, B., et al. (2014). Embryonic and adult-derived resident cardiac macrophages are maintained through distinct mechanisms at steady state and during inflammation. Immunity 40, 91-104.doi: 10.1016/j.immuni.2013.11.019

Esterházy, D., Loschko, J., London, M., Jove, V., Oliveira, T. Y., Mucida, D., et al. (2016). Classical dendritic cells are required for dietary antigen-mediated induction of peripheral T(reg) cells and tolerance. Nat. Immunol. 17, 545555.doi: 10.1038/ni.3408

Fassarella, M., Blaak, E. E., Penders, J., Nauta, A., Smidt, H., Zoetendal, E. G., et al. (2020). Gut microbiome stability and resilience: elucidating the response to perturbations in order to modulate gut health. Gut 70, 595-605. doi: 10.1136/ gutjnl-2020-321747

Festuccia, W. T., Pouliot, P., Bakan, I., Sabatini, D. M., and Laplante, M. (2014). Myeloid-specific Rictor deletion induces M1 macrophage polarization and potentiates in vivo pro-inflammatory response to lipopolysaccharide. PLoS One 9:e95432.doi: 10.1371/journal.pone.0095432

Frank, D. N., St Amand, A. L., Feldman, R. A., Boedeker, E. C., Harpaz, N., Pace, N. R., et al. (2007). Molecular-phylogenetic characterization of microbial community imbalances in human inflammatory bowel diseases. Proc. Natl. Acad. Sci. U.S.A. 104, 13780-13785.doi: 10.1073/pnas.0706625104

Franzosa, E. A., Sirota-Madi, A., Avila-Pacheco, J., Fornelos, N., Haiser, H. J., Reinker, S., et al. (2019). Gut microbiome structure and metabolic activity in inflammatory bowel disease. Nat. Microbiol. 4, 293-305. doi: 10.1038/s41564018-0306-4

Friedrich, M., Pohin, M., and Powrie, F. (2019). Cytokine networks in the pathophysiology of inflammatory bowel disease. Immunity 50, 992-1006.doi: 10.1016/j.immuni.2019.03.017

Gabanyi, I., Muller, P. A., Feighery, L., Oliveira, T. Y., Costa-Pinto, F. A., Mucida, D., et al. (2016). Neuro-immune interactions drive tissue programming in intestinal macrophages. Cell 164, 378-391.doi: 10.1016/j.cell.2015.12.023 
Garcia-Carbonell, R., Wong, J., Kim, J. Y., Close, L. A., Boland, B. S., Wong, T. L., et al. (2018). Elevated A20 promotes TNF-induced and RIPK1-dependent intestinal epithelial cell death. Proc. Natl. Acad. Sci. U.S.A. 115, E9192-E9200. doi: $10.1073 /$ pnas.1810584115

Gaudino, S. J., and Kumar, P. (2019). Cross-talk between antigen presenting cells and $\mathrm{t}$ cells impacts intestinal homeostasis, bacterial infections, and tumorigenesis. Front. Immunol. 10:360. doi: 10.3389/fimmu.2019.00360

Geissmann, F., Jung, S., and Littman, D. R. (2003). Blood monocytes consist of two principal subsets with distinct migratory properties. Immunity 19, 71-82.doi: 10.1016/s1074-7613(03)00174-2

Geremia, A., and Arancibia-Cárcamo, C. V. (2017). Innate lymphoid cells in intestinal inflammation. Front. Immunol. 8:1296. doi: 10.3389/fimmu.2017. 01296

Geremia, A., Biancheri, P., Allan, P., Corazza, G. R., and Di Sabatino, A. (2014). Innate and adaptive immunity in inflammatory bowel disease. Autoimmun. Rev. 13, 3-10. doi: 10.1016/j.autrev.2013.06.004

Gevers, D., Kugathasan, S., Denson, L. A., Vázquez-Baeza, Y., Van Treuren, W., Ren, B., et al. (2014). The treatment-naive microbiome in new-onset Crohn's disease. Cell Host. Microbe. 15, 382-392. doi: 10.1016/j.chom.2014.02.005

Grainger, J. R., Konkel, J. E., Zangerle-Murray, T., and Shaw, T. N. (2017). Macrophages in gastrointestinal homeostasis and inflammation. Pflugers Arch. 469, 527-539.doi: 10.1007/s00424-017-1958-2

Grainger, J. R., Wohlfert, E. A., Fuss, I. J., Bouladoux, N., Askenase, M. H., Legrand, F., et al. (2013). Inflammatory monocytes regulate pathologic responses to commensals during acute gastrointestinal infection. Nat. Med. 19, 713-721.doi: 10.1038/nm.3189

Gren, S. T., and Grip, O. (2016). Role of monocytes and intestinal macrophages in crohn's disease and ulcerative colitis. Inflamm. Bowel. Dis. 22, 1992-1998.doi: 10.1097/mib.0000000000000824

Guan, G., Ding, S., Yin, Y., Duraipandiyan, V., Al-Dhabi, N. A., Liu, G., et al. (2019). Macleaya cordata extract alleviated oxidative stress and altered innate immune response in mice challenged with enterotoxigenic Escherichia coli. Sci. China Life Sci. 62, 1019-1027.doi: 10.1007/s11427-018-9494-6

Guo, L., Xu, X. Q., Zhou, L., Zhou, R. H., Wang, X., Li, J. L., et al. (2018). Human intestinal epithelial cells release antiviral factors that inhibit HIV infection of macrophages. Front. Immunol. 9:247. doi: 10.3389/fimmu.2018.00247

Hadis, U., Wahl, B., Schulz, O., Hardtke-Wolenski, M., Schippers, A., Wagner, N., et al. (2011). Intestinal tolerance requires gut homing and expansion of FoxP3+ regulatory $\mathrm{T}$ cells in the lamina propria. Immunity 34, 237-246.doi: 10.1016/j.immuni.2011.01.016

Hashimoto, D., Chow, A., Noizat, C., Teo, P., Beasley, M. B., Leboeuf, M., et al. (2013). Tissue-resident macrophages self-maintain locally throughout adult life with minimal contribution from circulating monocytes. Immunity 38, 792-804.doi: 10.1016/j.immuni.2013.04.004

Hewison, M. (2012). An update on vitamin D and human immunity. Clin. Endocrinol. (Oxf) 76, 315-325.doi: 10.1111/j.1365-2265.2011.04261.x

Hidalgo-Garcia, L., Galvez, J., Rodriguez-Cabezas, M. E., and Anderson, P. O. (2018). Can a conversation between mesenchymal stromal cells and macrophages solve the crisis in the inflamed intestine? Front. Pharmacol. 9:179. doi: 10.3389/fphar.2018.00179

Hill, D. A., and Artis, D. (2010). Intestinal bacteria and the regulation of immune cell homeostasis. Annu. Rev. Immunol. 28, 623-667.doi: 10.1146/annurevimmunol-030409-101330

Hosomi, S., Kaser, A., and Blumberg, R. S. (2015). Role of endoplasmic reticulum stress and autophagy as interlinking pathways in the pathogenesis of inflammatory bowel disease. Curr. Opin. Gastroenterol. 31, 81-88.doi: 10.1097/ mog.0000000000000144

Huang, Y., Qi, H., Zhang, Z., Wang, E., Yun, H., Yan, H., et al. (2017). Gut REG3 $\gamma$ associated lactobacillus induces anti-inflammatory macrophages to maintain adipose tissue homeostasis. Front. Immunol. 8:1063. doi: 10.3389/fimmu.2017. 01063

Hundertmark, J., Krenkel, O., and Tacke, F. (2018). Adapted immune responses of myeloid-derived cells in fatty liver disease. Front. Immunol. 9:2418. doi: 10.3389/fimmu.2018.02418

Isidro, R. A., and Appleyard, C. B. (2016). Colonic macrophage polarization in homeostasis, inflammation, and cancer. Am. J. Physiol. Gastrointest Liver Physiol. 311, G59-G73. doi: 10.1152/ajpgi.00123.2016
Italiani, P., and Boraschi, D. (2014). From monocytes to M1/M2 macrophages: phenotypical vs. functional differentiation. Front. Immunol. 5:514. doi: 10.3389/ fimmu.2014.00514

Jain, N., Moeller, J., and Vogel, V. (2019). Mechanobiology of macrophages: how physical factors coregulate macrophage plasticity and phagocytosis. Annu. Rev. Biomed. Eng. 21, 267-297.doi: 10.1146/annurev-bioeng-062117-121224

Joeris, T., Müller-Luda, K., Agace, W. W., and Mowat, A. M. (2017). Diversity and functions of intestinal mononuclear phagocytes. Mucosal. Immunol. 10, 845-864.doi: 10.1038/mi.2017.22

Johansson, M. E., and Hansson, G. C. (2016). Immunological aspects of intestinal mucus and mucins. Nat. Rev. Immunol. 16, 639-649.doi: 10.1038/nri.2016.88

Johansson, M. E., Sjövall, H., and Hansson, G. C. (2013). The gastrointestinal mucus system in health and disease. Nat. Rev. Gastroenterol. Hepatol. 10, 352-361.doi: 10.1038/nrgastro.2013.35

Jones, G. R., Bain, C. C., Fenton, T. M., Kelly, A., Brown, S. L., Ivens, A. C., et al. (2018). Dynamics of colon monocyte and macrophage activation during colitis. Front. Immunol. 9:2764. doi: 10.3389/fimmu.2018.02764

Kamada, N., Hisamatsu, T., Honda, H., Kobayashi, T., Chinen, H., Kitazume, M. T., et al. (2009). Human CD14+ macrophages in intestinal lamina propria exhibit potent antigen-presenting ability. J. Immunol. 183, 1724-1731.doi: 10. 4049/jimmunol.0804369

Kamada, N., Hisamatsu, T., Okamoto, S., Chinen, H., Kobayashi, T., Sato, T., et al. (2008). Unique CD14 intestinal macrophages contribute to the pathogenesis of Crohn disease via IL-23/IFN-gamma axis. J. Clin. Invest. 118, 2269-2280. doi: $10.1172 /$ jci34610

Kaneda, M. M., Messer, K. S., Ralainirina, N., Li, H., Leem, C. J., Gorjestani, S., et al. (2016). PI3K $\gamma$ is a molecular switch that controls immune suppression. Nature 539, 437-442. doi: 10.1038/nature19834

Karin, M., and Clevers, H. (2016). Reparative inflammation takes charge of tissue regeneration. Nature 529, 307-315.doi: 10.1038/nature17039

Khor, B., Gardet, A., and Xavier, R. J. (2011). Genetics and pathogenesis of inflammatory bowel disease. Nature 474, 307-317. doi: 10.1038/nature10209

Kim, M., Galan, C., Hill, A. A., Wu, W. J., Fehlner-Peach, H., Song, H. W., et al. (2018). Critical role for the microbiota in CX(3)CR1(+) intestinal mononuclear phagocyte regulation of intestinal t cell responses. Immunity 49, 151-163.e5. doi: 10.1016/j.immuni.2018.05.009

Kostic, A. D., Xavier, R. J., and Gevers, D. (2014). The microbiome in inflammatory bowel disease: current status and the future ahead. Gastroenterology 146, 1489-1499.doi: 10.1053/j.gastro.2014.02.009

Lee, J. C., Biasci, D., Roberts, R., Gearry, R. B., Mansfield, J. C., Ahmad, T., et al. (2017). Genome-wide association study identifies distinct genetic contributions to prognosis and susceptibility in Crohn's disease. Nat. Genet. 49, 262-268.doi: 10.1038/ng.3755

Lee, S. H., Starkey, P. M., and Gordon, S. (1985). Quantitative analysis of total macrophage content in adult mouse tissues. Immunochemical studies with monoclonal antibody F4/80. J. Exp. Med. 161, 475-489.doi: 10.1084/jem.161. 3.475

Leonardi, I., Li, X., Semon, A., Li, D., Doron, I., Putzel, G., et al. (2018). CX3CR1(+) mononuclear phagocytes control immunity to intestinal fungi. Science 359, 232-236.doi: 10.1126/science.aao1503

Lepage, P., Häsler, R., Spehlmann, M. E., Rehman, A., Zvirbliene, A., Begun, A., et al. (2011). Twin study indicates loss of interaction between microbiota and mucosa of patients with ulcerative colitis. Gastroenterology 141, 227-236.doi: 10.1053/j.gastro.2011.04.011

Ley, K., Pramod, A. B., Croft, M., Ravichandran, K. S., and Ting, J. P. (2016). How mouse macrophages sense what is going on. Front. Immunol. 7:204. doi: 10.3389/fimmu.2016.00204

Li, J., Zhang, J., Guo, H., Yang, S., Fan, W., Ye, N., et al. (2018). Critical role of alternative M2 Skewing in miR-155 deletion-mediated protection of colitis. Front. Immunol. 9:904. doi: 10.3389/fimmu.2018.00904

Li, M., Lin, J., Wang, Z., He, S., Ma, X., Li, D., et al. (2010). Oxidized low-density lipoprotein-induced proinflammatory cytokine response in macrophages are suppressed by $\mathrm{CD} 4 \mathrm{CD} 25(+)$ Foxp3(+) regulatory $\mathrm{T}$ cells through downregulating toll like receptor 2-mediated activation of NF-kappaB. Cell Physiol. Biochem. 25, 649-656.doi: 10.1159/000315084

Liang, H., Jiang, B., Manne, S., Lissoos, T., Bennett, D., Dolin, P., et al. (2018). Risk factors for postoperative infection after gastrointestinal surgery among adult 
patients with inflammatory bowel disease: findings from a large observational US cohort study. JGH Open 2, 182-190.doi: 10.1002/jgh3.12072

Linkermann, A., and Green, D. R. (2014). Necroptosis. N. Engl. J. Med. 370, 455-465. doi: 10.1056/NEJMra1310050

Lissner, D., Schumann, M., Batra, A., Kredel, L. I., Kühl, A. A., Erben, U., et al. (2015). Monocyte and M1 macrophage-induced barrier defect contributes to chronic intestinal inflammation in IBD. Inflamm. Bowel. Dis. 21, 1297-1305. doi: 10.1097/mib.0000000000000384

Litinskiy, M. B., Nardelli, B., Hilbert, D. M., He, B., Schaffer, A., Casali, P., et al. (2002). DCs induce CD40-independent immunoglobulin class switching through BLyS and APRIL. Nat. Immunol. 3, 822-829.doi: 10.1038/ni829

Liu, T. C., and Stappenbeck, T. S. (2016). Genetics and pathogenesis of inflammatory bowel disease. Annu. Rev. Pathol. 11, 127-148. doi: 10.1146/ annurev-pathol-012615-044152

Lloyd-Price, J., Arze, C., Ananthakrishnan, A. N., Schirmer, M., Avila-Pacheco, J., Poon, T. W., et al. (2019). Multi-omics of the gut microbial ecosystem in inflammatory bowel diseases. Nature 569, 655-662. doi: 10.1038/s41586-0191237-9

Loschko, J., Schreiber, H. A., Rieke, G. J., Esterházy, D., Meredith, M. M., Pedicord, V. A., et al. (2016). Absence of MHC class II on cDCs results in microbialdependent intestinal inflammation. J. Exp. Med. 213, 517-534.doi: 10.1084/jem. 20160062

Lu, Y., Li, X., Liu, S., Zhang, Y., and Zhang, D. (2018). Toll-like receptors and inflammatory bowel disease. Front. Immunol. 9:72. doi: 10.3389/fimmu.2018. 00072

Luu, M., Steinhoff, U., and Visekruna, A. (2017). Functional heterogeneity of gutresident regulatory T cells. Clin. Transl. Immunol. 6:e156.doi: 10.1038/cti.2017. 39

Ma, J., Zheng, Y., Tang, W., Yan, W., Nie, H., Fang, J., et al. (2020a). Dietary polyphenols in lipid metabolism: a role of gut microbiome. Anim. Nutr. 6, 404-409.doi: 10.1016/j.aninu.2020.08.002

Ma, Y., Hu, C., Yan, W., Jiang, H., and Liu, G. (2020b). Lactobacillus pentosus increases the abundance of akkermansia and affects the serum metabolome to alleviate DSS-induced colitis in a murine model. Front. Cell Dev. Biol. 8:591408. doi: 10.3389/fcell.2020.591408

Macpherson, A. J., Yilmaz, B., Limenitakis, J. P., and Ganal-Vonarburg, S. C. (2018). IgA function in relation to the intestinal microbiota. Annu. Rev. Immunol. 36, 359-381.doi: 10.1146/annurev-immunol-042617-053238

Magnusson, M. K., Brynjólfsson, S. F., Dige, A., Uronen-Hansson, H., Börjesson, L. G., Bengtsson, J. L., et al. (2016). Macrophage and dendritic cell subsets in IBD: ALDH+ cells are reduced in colon tissue of patients with ulcerative colitis regardless of inflammation. Mucosal. Immunol. 9, 171-182.doi: 10.1038/ mi.2015.48

Maloy, K. J., and Powrie, F. (2011). Intestinal homeostasis and its breakdown in inflammatory bowel disease. Nature 474, 298-306.doi: 10.1038/nature10208

Mantovani, A., Sica, A., Sozzani, S., Allavena, P., Vecchi, A., Locati, M., et al. (2004). The chemokine system in diverse forms of macrophage activation and polarization. Trends Immunol. 25, 677-686.doi: 10.1016/j.it.2004.09.015

Martens, E. C., Neumann, M., and Desai, M. S. (2018). Interactions of commensal and pathogenic microorganisms with the intestinal mucosal barrier. Nat. Rev. Microbiol. 16, 457-470.doi: 10.1038/s41579-018-0036-x

Martin, J. C., Chang, C., Boschetti, G., Ungaro, R., Giri, M., Grout, J. A., et al. (2019). Single-cell analysis of crohn's disease lesions identifies a pathogenic cellular module associated with resistance to anti-TNF therapy. Cell 178, 14931508.e20. doi: 10.1016/j.cell.2019.08.008

Martinez, F. O., and Gordon, S. (2014). The M1 and M2 paradigm of macrophage activation: time for reassessment. F1000Prime Rep. 6:13. doi: 10.12703/p6-13

Mills, C. D., Kincaid, K., Alt, J. M., Heilman, M. J., and Hill, A. M. (2000). M-1/M2 macrophages and the Th1/Th2 paradigm. J. Immunol. 164, 6166-6173.doi: 10.4049/jimmunol.164.12.6166

Mosser, D. M., and Edwards, J. P. (2008). Exploring the full spectrum of macrophage activation. Nat. Rev. Immunol. 8, 958-969.doi: 10.1038/nri2448

Mowat, A. M. (2018). To respond or not to respond - a personal perspective of intestinal tolerance. Nat. Rev. Immunol. 18, 405-415.doi: 10.1038/s41577-0180002-x

Mowat, A. M., and Bain, C. C. (2011). Mucosal macrophages in intestinal homeostasis and inflammation. J. Innate. Immun. 3, 550-564.doi: 10.1159/ 000329099
Muller, P. A., Koscsó, B., Rajani, G. M., Stevanovic, K., Berres, M. L., Hashimoto, D., et al. (2014). Crosstalk between muscularis macrophages and enteric neurons regulates gastrointestinal motility. Cell 158, 300-313.doi: 10.1016/j.cell. 2014.04.050

Murray, P. J. (2017). Macrophage Polarization. Annu. Rev. Physiol. 79, 541-566. doi: 10.1146/annurev-physiol-022516-034339

Murray, P. J., Allen, J. E., Biswas, S. K., Fisher, E. A., Gilroy, D. W., Goerdt, S., et al. (2014). Macrophage activation and polarization: nomenclature and experimental guidelines. Immunity 41, 14-20.doi: 10.1016/j.immuni.2014.06. 008

Murray, P. J., and Smale, S. T. (2012). Restraint of inflammatory signaling by interdependent strata of negative regulatory pathways. Nat. Immunol. 13, 916-924.doi: 10.1038/ni.2391

Nagashima, R., Maeda, K., Imai, Y., and Takahashi, T. (1996). Lamina propria macrophages in the human gastrointestinal mucosa: their distribution, immunohistological phenotype, and function. J. Histochem. Cytochem. 44, 721-731.doi: 10.1177/44.7.8675993

Ni, J., Wu, G. D., Albenberg, L., and Tomov, V. T. (2017). Gut microbiota and IBD: causation or correlation? Nat. Rev. Gastroenterol. Hepatol. 14, 573-584.doi: 10.1038/nrgastro.2017.88

Nutsch, K., Chai, J. N., Ai, T. L., Russler-Germain, E., Feehley, T., Nagler, C. R., et al. (2016). Rapid and efficient generation of regulatory t cells to commensal antigens in the periphery. Cell Rep. 17, 206-220.doi: 10.1016/j.celrep.2016.08. 092

Odenwald, M. A., and Turner, J. R. (2017). The intestinal epithelial barrier: a therapeutic target? Nat. Rev. Gastroenterol. Hepatol. 14, 9-21.doi: 10.1038/ nrgastro.2016.169

Ogino, T., Nishimura, J., Barman, S., Kayama, H., Uematsu, S., Okuzaki, D., et al. (2013). Increased Th17-inducing activity of CD14+ CD163 low myeloid cells in intestinal lamina propria of patients with Crohn's disease. Gastroenterology 145, 1380-1391.e1. doi: 10.1053/j.gastro.2013.08.049

Okumura, R., and Takeda, K. (2017). Roles of intestinal epithelial cells in the maintenance of gut homeostasis. Exp. Mol. Med. 49:e338.doi: 10.1038/emm. 2017.20

Ortega-Gómez, A., Perretti, M., and Soehnlein, O. (2013). Resolution of inflammation: an integrated view. EMBO Mol. Med. 5, 661-674.doi: 10.1002/ emmm.201202382

Pabst, O., and Mowat, A. M. (2012). Oral tolerance to food protein. Mucosal. Immunol. 5, 232-239.doi: 10.1038/mi.2012.4

Peterson, L. W., and Artis, D. (2014). Intestinal epithelial cells: regulators of barrier function and immune homeostasis. Nat. Rev. Immunol. 14, 141-153.doi: 10. 1038/nri3608

Piacenza, L., Trujillo, M., and Radi, R. (2019). Reactive species and pathogen antioxidant networks during phagocytosis. J. Exp. Med. 216, 501-516.doi: 10. 1084/jem.20181886

Platt, A. M., Bain, C. C., Bordon, Y., Sester, D. P., and Mowat, A. M. (2010). An independent subset of TLR expressing CCR2-dependent macrophages promotes colonic inflammation. J. Immunol. 184, 6843-6854.doi: 10.4049/ jimmunol.0903987

Popov, A., Driesen, J., Abdullah, Z., Wickenhauser, C., Beyer, M., Debey-Pascher, S., et al. (2008). Infection of myeloid dendritic cells with Listeria monocytogenes leads to the suppression of $\mathrm{T}$ cell function by multiple inhibitory mechanisms. J. Immunol. 181, 4976-4988.doi: 10.4049/jimmunol.181.7.4976

Pull, S. L., Doherty, J. M., Mills, J. C., Gordon, J. I., and Stappenbeck, T. S. (2005). Activated macrophages are an adaptive element of the colonic epithelial progenitor niche necessary for regenerative responses to injury. Proc. Natl. Acad. Sci. U.S.A. 102, 99-104.doi: 10.1073/pnas.0405979102

Qin, N., Yang, F., Li, A., Prifti, E., Chen, Y., Shao, L., et al. (2014). Alterations of the human gut microbiome in liver cirrhosis. Nature 513, 59-64. doi: 10.1038/ nature 13568

Rabbi, M. F., Eissa, N., Munyaka, P. M., Kermarrec, L., Elgazzar, O., Khafipour, E., et al. (2017). Reactivation of intestinal inflammation is suppressed by catestatin in a murine model of colitis via M1 macrophages and not the gut microbiota. Front. Immunol. 8:985. doi: 10.3389/fimmu.2017.00985

Ramachandran, A., Mcgill, M. R., Xie, Y., Ni, H. M., Ding, W. X., Jaeschke, H., et al. (2013). Receptor interacting protein kinase 3 is a critical early mediator of acetaminophen-induced hepatocyte necrosis in mice. Hepatology 58, 20992108.doi: 10.1002/hep.26547 
Ramakrishnan, S. K., and Shah, Y. M. (2016). Role of intestinal HIF-2 $\alpha$ in health and disease. Annu. Rev. Physiol. 78, 301-325.doi: 10.1146/annurev-physiol021115-105202

Ramesh, R., Kozhaya, L., Mckevitt, K., Djuretic, I. M., Carlson, T. J., Quintero, M. A., et al. (2014). Pro-inflammatory human Th17 cells selectively express P-glycoprotein and are refractory to glucocorticoids. J. Exp. Med. 211, 89104.doi: $10.1084 /$ jem.20130301

Rieder, F., and Fiocchi, C. (2009). Intestinal fibrosis in IBD-a dynamic, multifactorial process. Nat. Rev. Gastroenterol. Hepatol. 6, 228-235.doi: 10. 1038/nrgastro.2009.31

Rieder, F., Fiocchi, C., and Rogler, G. (2017). Mechanisms, management, and treatment of fibrosis in patients with inflammatory bowel diseases. Gastroenterology 152, 340-350.e6. doi: 10.1053/j.gastro.2016.09.047

Rivollier, A., He, J., Kole, A., Valatas, V., and Kelsall, B. L. (2012). Inflammation switches the differentiation program of Ly6Chi monocytes from antiinflammatory macrophages to inflammatory dendritic cells in the colon. J. Exp. Med. 209, 139-155.doi: 10.1084/jem.20101387

Roychowdhury, S., Mcmullen, M. R., Pisano, S. G., Liu, X., and Nagy, L. E. (2013). Absence of receptor interacting protein kinase 3 prevents ethanol-induced liver injury. Hepatology 57, 1773-1783.doi: 10.1002/hep.26200

Rugtveit, J., Bakka, A., and Brandtzaeg, P. (1997). Differential distribution of B7.1 (CD80) and B7.2 (CD86) costimulatory molecules on mucosal macrophage subsets in human inflammatory bowel disease (IBD). Clin. Exp. Immunol. 110, 104-113.doi: 10.1046/j.1365-2249.1997.5071404.x

Salvador, P., Macías-Ceja, D. C., Gisbert-Ferrándiz, L., Hernández, C., Bernardo, D., Alós, R., et al. (2018). CD16+ Macrophages mediate fibrosis in inflammatory bowel disease. J. Crohns. Colitis 12, 589-599.doi: 10.1093/ecco-jcc/jjx185

Samadder, N. J., Valentine, J. F., Guthery, S., Singh, H., Bernstein, C. N., Leighton, J. A., et al. (2019). Family History associates with increased risk of colorectal cancer in patients with inflammatory bowel diseases. Clin. Gastroenterol. Hepatol. 17, 1807-1813.e1. doi: 10.1016/j.cgh.2018.09.038

Sanders, T. J., Mccarthy, N. E., Giles, E. M., Davidson, K. L., Haltalli, M. L., Hazell, S., et al. (2014). Increased production of retinoic acid by intestinal macrophages contributes to their inflammatory phenotype in patients with Crohn's disease. Gastroenterology 146, 1278-1288.e1-2. doi: 10.1053/j.gastro.2014.01.057

Scharl, S., Barthel, C., Rossel, J. B., Biedermann, L., Misselwitz, B., Schoepfer, A. M., et al. (2019). Malignancies in inflammatory bowel disease: frequency, incidence and risk factors-results from the swiss IBD cohort study. Am. J. Gastroenterol. 114, 116-126.doi: 10.1038/s41395-018-0360-9

Scheibe, K., Kersten, C., Schmied, A., Vieth, M., Primbs, T., Carlé, B., et al. (2019). Inhibiting interleukin 36 receptor signaling reduces fibrosis in mice with chronic intestinal inflammation. Gastroenterology 156, 1082-1097.e11. doi: 10.1053/j.gastro.2018.11.029

Schenk, M., Bouchon, A., Seibold, F., and Mueller, C. (2007). TREM-1-expressing intestinal macrophages crucially amplify chronic inflammation in experimental colitis and inflammatory bowel diseases. J. Clin. Invest. 117, 3097-3106.doi: $10.1172 /$ jci30602

Schett, G., and Neurath, M. F. (2018). Resolution of chronic inflammatory disease: universal and tissue-specific concepts. Nat. Commun. 9:3261. doi: 10.1038/ s41467-018-05800-6

Schierwagen, R., Uschner, F. E., Ortiz, C., Torres, S., Brol, M. J., Tyc, O., et al. (2020). The role of macrophage-inducible C-Type lectin in different stages of chronic liver disease. Front. Immunol. 11:1352. doi: 10.3389/fimmu.2020.01352

Schippers, A., Muschaweck, M., Clahsen, T., Tautorat, S., Grieb, L., Tenbrock, K., et al. (2016). $\beta 7$-Integrin exacerbates experimental DSS-induced colitis in mice by directing inflammatory monocytes into the colon. Mucosal. Immunol. 9 , 527-538.doi: $10.1038 / \mathrm{mi} .2015 .82$

Schridde, A., Bain, C. C., Mayer, J. U., Montgomery, J., Pollet, E., Denecke, B., et al. (2017). Tissue-specific differentiation of colonic macrophages requires TGF $\beta$ receptor-mediated signaling. Mucosal. Immunol. 10, 1387-1399.doi: 10.1038/ mi.2016.142

Schulthess, J., Meresse, B., Ramiro-Puig, E., Montcuquet, N., Darche, S., Bègue, B., et al. (2012). Interleukin-15-dependent NKp46+ innate lymphoid cells control intestinal inflammation by recruiting inflammatory monocytes. Immunity 37 , 108-121.doi: 10.1016/j.immuni.2012.05.013

Schulz, C., Gomez Perdiguero, E., Chorro, L., Szabo-Rogers, H., Cagnard, N., Kierdorf, K., et al. (2012). A lineage of myeloid cells independent of Myb and hematopoietic stem cells. Science 336, 86-90.doi: 10.1126/science.1219179
Schwerd, T., Pandey, S., Yang, H. T., Bagola, K., Jameson, E., Jung, J., et al. (2017). Impaired antibacterial autophagy links granulomatous intestinal inflammation in Niemann-Pick disease type C1 and XIAP deficiency with NOD2 variants in Crohn's disease. Gut 66, 1060-1073.doi: 10.1136/gutjnl-2015-310382

Seo, S. U., Kamada, N., Muñoz-Planillo, R., Kim, Y. G., Kim, D., Koizumi, Y., et al. (2015). Distinct commensals induce interleukin-1 $\beta$ via NLRP3 inflammasome in inflammatory monocytes to promote intestinal inflammation in response to injury. Immunity 42, 744-755.doi: 10.1016/j.immuni.2015.03.004

Sheng, J., Ruedl, C., and Karjalainen, K. (2015). Most tissue-resident macrophages except microglia are derived from fetal hematopoietic stem cells. Immunity 43 , 382-393.doi: 10.1016/j.immuni.2015.07.016

Shkoda, A., Ruiz, P. A., Daniel, H., Kim, S. C., Rogler, G., Sartor, R. B., et al. (2007). Interleukin-10 blocked endoplasmic reticulum stress in intestinal epithelial cells: impact on chronic inflammation. Gastroenterology 132, 190-207.doi: 10. 1053/j.gastro.2006.10.030

Smillie, C. S., Biton, M., Ordovas-Montanes, J., Sullivan, K. M., Burgin, G., Graham, D. B., et al. (2019). Intra- and inter-cellular rewiring of the human colon during ulcerative colitis. Cell 178, 714-730.e22. doi: 10.1016/j.cell.2019.06.029

Smith, A. M., Rahman, F. Z., Hayee, B., Graham, S. J., Marks, D. J., Sewell, G. W., et al. (2009). Disordered macrophage cytokine secretion underlies impaired acute inflammation and bacterial clearance in Crohn's disease. J. Exp. Med. 206, 1883-1897.doi: 10.1084/jem.20091233

Smith, P., Mangan, N. E., Walsh, C. M., Fallon, R. E., Mckenzie, A. N., Van Rooijen, N., et al. (2007). Infection with a helminth parasite prevents experimental colitis via a macrophage-mediated mechanism. J. Immunol. 178, 4557-4566.doi: 10.4049/jimmunol.178.7.4557

Stein, M., Keshav, S., Harris, N., and Gordon, S. (1992). Interleukin 4 potently enhances murine macrophage mannose receptor activity: a marker of alternative immunologic macrophage activation. J. Exp. Med. 176, 287-292.doi: 10.1084/jem.176.1.287

Strauss-Ayali, D., Conrad, S. M., and Mosser, D. M. (2007). Monocyte subpopulations and their differentiation patterns during infection. J. Leukoc. Biol. 82, 244-252.doi: 10.1189/jlb.0307191

Sugimoto, M. A., Vago, J. P., Perretti, M., and Teixeira, M. M. (2019). Mediators of the resolution of the inflammatory response. Trends Immunol. 40, 212-227.doi: 10.1016/j.it.2019.01.007

Sun, M., He, C., Cong, Y., and Liu, Z. (2015). Regulatory immune cells in regulation of intestinal inflammatory response to microbiota. Mucosal. Immunol. 8, 969978.doi: 10.1038/mi.2015.49

Tajima, T., Murata, T., Aritake, K., Urade, Y., Michishita, M., Matsuoka, T., et al. (2012). EP2 and EP4 receptors on muscularis resident macrophages mediate LPS-induced intestinal dysmotility via iNOS upregulation through cAMP/ERK signals. Am. J. Physiol. Gastrointest Liver Physiol. 302, G524-G534. doi: 10.1152/ ajpgi.00264.2011

Takada, Y., Hisamatsu, T., Kamada, N., Kitazume, M. T., Honda, H., Oshima, Y., et al. (2010). Monocyte chemoattractant protein-1 contributes to gut homeostasis and intestinal inflammation by composition of IL-10-producing regulatory macrophage subset. J. Immunol. 184, 2671-2676.doi: 10.4049/ jimmunol.0804012

Tamoutounour, S., Henri, S., Lelouard, H., De Bovis, B., De Haar, C., Van Der Woude, C. J., et al. (2012). CD64 distinguishes macrophages from dendritic cells in the gut and reveals the Th1-inducing role of mesenteric lymph node macrophages during colitis. Eur. J. Immunol. 42, 3150-3166.doi: 10.1002/eji. 201242847

Tang, M., Xie, Q., Gimple, R. C., Zhong, Z., Tam, T., Tian, J., et al. (2020). Three-dimensional bioprinted glioblastoma microenvironments model cellular dependencies and immune interactions. Cell Res. 30, 833-853.doi: 10.1038/ s41422-020-0338-1

Thiesen, S., Janciauskiene, S., Uronen-Hansson, H., Agace, W., Högerkorp, C. M., Spee, P., et al. (2014). CD14(hi)HLA-DR(dim) macrophages, with a resemblance to classical blood monocytes, dominate inflamed mucosa in Crohn's disease. J. Leukoc. Biol. 95, 531-541.doi: 10.1189/jlb.0113021

Thomas, A. C., and Mattila, J. T. (2014). "Of mice and men": arginine metabolism in macrophages. Front. Immunol. 5:479. doi: 10.3389/fimmu.2014.00479

Tordesillas, L., and Berin, M. C. (2018). Mechanisms of oral tolerance. Clin. Rev. Allergy Immunol. 55, 107-117. doi: 10.1007/s12016-018-8680-5

Torres, J., Mehandru, S., Colombel, J. F., and Peyrin-Biroulet, L. (2017). Crohn's disease. Lancet 389, 1741-1755. doi: 10.1016/s0140-6736(16)31711-1 
Ungaro, R., Mehandru, S., Allen, P. B., Peyrin-Biroulet, L., and Colombel, J. F. (2017). Ulcerative colitis. Lancet 389, 1756-1770. doi: 10.1016/s0140-6736(16) 32126-2

Uno, J. K., Rao, K. N., Matsuoka, K., Sheikh, S. Z., Kobayashi, T., Li, F., et al. (2010). Altered macrophage function contributes to colitis in mice defective in the phosphoinositide-3 kinase subunit p1108. Gastroenterology 139, 1642-1653, 1653.e1-6. doi: 10.1053/j.gastro.2010.07.008

van Furth, R., and Cohn, Z. A. (1968). The origin and kinetics of mononuclear phagocytes. J. Exp. Med. 128, 415-435.doi: 10.1084/jem.128.3.415

van Furth, R., Cohn, Z. A., Hirsch, J. G., Humphrey, J. H., Spector, W. G., Langevoort, H. L., et al. (1972). The mononuclear phagocyte system: a new classification of macrophages, monocytes, and their precursor cells. Bull. World Health Organ. 46, 845-852.

VanDussen, K. L., Stojmirović, A., Li, K., Liu, T. C., Kimes, P. K., Muegge, B. D., et al. (2018). Abnormal small intestinal epithelial microvilli in patients with crohn's disease. Gastroenterology 155, 815-828.doi: 10.1053/j.gastro.2018.05. 028

Vannella, K. M., and Wynn, T. A. (2017). Mechanisms of organ injury and repair by macrophages. Annu. Rev. Physiol. 79, 593-617.doi: 10.1146/annurev-physiol022516-034356

Varol, C., Vallon-Eberhard, A., Elinav, E., Aychek, T., Shapira, Y., Luche, H., et al. (2009). Intestinal lamina propria dendritic cell subsets have different origin and functions. Immunity 31, 502-512.doi: 10.1016/j.immuni.2009.06.025

Vigorito, E., Kohlhaas, S., Lu, D., and Leyland, R. (2013). miR-155: an ancient regulator of the immune system. Immunol. Rev. 253, 146-157.doi: 10.1111/imr. 12057

Vos, A. C., Wildenberg, M. E., Arijs, I., Duijvestein, M., Verhaar, A. P., De Hertogh, G., et al. (2012). Regulatory macrophages induced by infliximab are involved in healing in vivo and in vitro. Inflamm. Bowel Dis. 18, 401-408.doi: 10.1002/ibd. 21818

Waddell, A., Ahrens, R., Steinbrecher, K., Donovan, B., Rothenberg, M. E., Munitz, A., et al. (2011). Colonic eosinophilic inflammation in experimental colitis is mediated by Ly6C(high) CCR2(+) inflammatory monocyte/macrophagederived CCL11. J. Immunol. 186, 5993-6003.doi: 10.4049/jimmunol.1003844

Wallace, K. L., Zheng, L. B., Kanazawa, Y., and Shih, D. Q. (2014). Immunopathology of inflammatory bowel disease. World J. Gastroenterol. 20, 6-21.doi: 10.3748/wjg.v20.i1.6

Wang, Y., Wang, X., Li, J., Zhou, Y., and Ho, W. (2013). RIG-I activation inhibits HIV replication in macrophages. J. Leukoc. Biol. 94, 337-341.doi: 10.1189/jlb. 0313158

Wang, Z., Vaughan, T. Y., Zhu, W., Chen, Y., Fu, G., Medrzycki, M., et al. (2019). Gab2 and Gab3 redundantly suppress colitis by modulating macrophage and CD8(+) T-Cell activation. Front. Immunol. 10:486. doi: 10.3389/fimmu.2019. 00486

Wawrzyniak, M., O'mahony, L., and Akdis, M. (2017). Role of regulatory cells in oral tolerance. Allergy Asthma. Immunol. Res. 9, 107-115.doi: 10.4168/aair. 2017.9.2.107

Weber, B., Saurer, L., Schenk, M., Dickgreber, N., and Mueller, C. (2011). CX3CR1 defines functionally distinct intestinal mononuclear phagocyte subsets which maintain their respective functions during homeostatic and inflammatory conditions. Eur. J. Immunol. 41, 773-779. doi: 10.1002/eji.201040965

Wei, S., Zhou, H., Wang, Q., Zhou, S., Li, C., Liu, R., et al. (2019). RIP3 deficiency alleviates liver fibrosis by inhibiting ROCK1-TLR4-NF- $\mathrm{B}$ pathway in macrophages. Faseb J. 33, 11180-11193.doi: 10.1096/fj.201900752R

Weiner, H. L. (2000). Oral tolerance, an active immunologic process mediated by multiple mechanisms. J. Clin. Invest. 106, 935-937.doi: 10.1172/jci11348

Weinhage, T., Däbritz, J., Brockhausen, A., Wirth, T., Brückner, M., Belz, M., et al. (2015). Granulocyte macrophage colony-stimulating factor-activated CD39(+)/CD73(+) murine monocytes modulate intestinal inflammation via induction of regulatory t cells. Cell Mol. Gastroenterol. Hepatol. 1, 433-449.e1. doi: 10.1016/j.jcmgh.2015.04.005

West, N. R., Hegazy, A. N., Owens, B. M. J., Bullers, S. J., Linggi, B., Buonocore, S., et al. (2017). Oncostatin $\mathrm{M}$ drives intestinal inflammation and predicts response to tumor necrosis factor-neutralizing therapy in patients with inflammatory bowel disease. Nat. Med. 23, 579-589.doi: 10.1038/nm.4307

Woehlbier, U., and Hetz, C. (2011). Modulating stress responses by the UPRosome: a matter of life and death. Trends Biochem. Sci. 36, 329-337.doi: 10.1016/j.tibs. 2011.03.001

Wu, W., He, C., Liu, C., Cao, A. T., Xue, X., Evans-Marin, H. L., et al. (2015). miR10a inhibits dendritic cell activation and Th1/Th17 cell immune responses in IBD. Gut 64, 1755-1764.doi: 10.1136/gutjnl-2014-307980

Xavier, R. J., and Podolsky, D. K. (2007). Unravelling the pathogenesis of inflammatory bowel disease. Nature 448, 427-434.doi: 10.1038/nature06005

Xue, J., Schmidt, S. V., Sander, J., Draffehn, A., Krebs, W., Quester, I., et al. (2014). Transcriptome-based network analysis reveals a spectrum model of human macrophage activation. Immunity 40, 274-288.doi: 10.1016/j.immuni.2014.01. 006

Yang, F. C., Chiu, P. Y., Chen, Y., Mak, T. W., and Chen, N. J. (2019). TREM-1dependent M1 macrophage polarization restores intestinal epithelium damaged by DSS-induced colitis by activating IL-22-producing innate lymphoid cells. J. Biomed. Sci. 26:46. doi: 10.1186/s12929-019-0539-4

Yona, S., Kim, K. W., Wolf, Y., Mildner, A., Varol, D., Breker, M., et al. (2013). Fate mapping reveals origins and dynamics of monocytes and tissue macrophages under homeostasis. Immunity 38, 79-91. doi: 10.1016/j.immuni.2012.12.001

Zeissig, S., Bojarski, C., Buergel, N., Mankertz, J., Zeitz, M., Fromm, M., et al. (2004). Downregulation of epithelial apoptosis and barrier repair in active Crohn's disease by tumour necrosis factor alpha antibody treatment. Gut 53, 1295-1302.doi: 10.1136/gut.2003.036632

Zhang, D., Shooshtarizadeh, P., Laventie, B. J., Colin, D. A., Chich, J. F., Vidic, J., et al. (2009). Two chromogranin a-derived peptides induce calcium entry in human neutrophils by calmodulin-regulated calcium independent phospholipase A2. PLoS One 4:e4501.doi: 10.1371/journal.pone.0004501

Zhang, W., Gu, Y., Chen, Y., Deng, H., Chen, L., Chen, S., et al. (2010). Intestinal flora imbalance results in altered bacterial translocation and liver function in rats with experimental cirrhosis. Eur. J. Gastroenterol. Hepatol. 22, 1481-1486. doi: 10.1097/MEG.0b013e32833eb8b0

Zhang, Y., Zhang, M., Li, X., Tang, Z., Wang, X., Zhong, M., et al. (2016). Silencing MicroRNA-155 attenuates cardiac injury and dysfunction in viral myocarditis via promotion of M2 phenotype polarization of macrophages. Sci. Rep. 6:22613. doi: 10.1038/srep22613

Zhou, X., Li, W., Wang, S., Zhang, P., Wang, Q., Xiao, J., et al. (2019). YAP aggravates inflammatory bowel disease by regulating M1/M2 macrophage polarization and gut microbial homeostasis. Cell Rep. 27, 1176-1189.e5. doi: 10.1016/j.celrep.2019.03.028

Zhou, Y., Guo, M., Wang, X., Li, J., Wang, Y., Ye, L., et al. (2013). TLR3 activation efficiency by high or low molecular mass poly I:C. Innate. Immun. 19, 184-192.doi: 10.1177/1753425912459975

Zigmond, E., Bernshtein, B., Friedlander, G., Walker, C. R., Yona, S., Kim, K. W., et al. (2014). Macrophage-restricted interleukin-10 receptor deficiency, but not IL-10 deficiency, causes severe spontaneous colitis. Immunity 40, 720-733.doi: 10.1016/j.immuni.2014.03.012

Zigmond, E., Varol, C., Farache, J., Elmaliah, E., Satpathy, A. T., Friedlander, G., et al. (2012). Ly6C hi monocytes in the inflamed colon give rise to proinflammatory effector cells and migratory antigen-presenting cells. Immunity 37, 1076-1090. doi: 10.1016/j.immuni.2012.08.026

Conflict of Interest: The authors declare that the research was conducted in the absence of any commercial or financial relationships that could be construed as a potential conflict of interest.

Copyright (c) 2021 Han, Ding, Jiang and Liu. This is an open-access article distributed under the terms of the Creative Commons Attribution License (CC BY). The use, distribution or reproduction in other forums is permitted, provided the original author(s) and the copyright owner(s) are credited and that the original publication in this journal is cited, in accordance with accepted academic practice. No use, distribution or reproduction is permitted which does not comply with these terms. 